Article

\title{
Design, Synthesis, and Biological Activity of Tetrahydrobenzo[4,5]thieno[2,3- $d]$ pyrimidine Derivatives as Anti-Inflammatory Agents
}

\author{
Yuan Zhang ${ }^{1,2,+}$ (D), Lu Luo ${ }^{1,+}$, Chao Han ${ }^{1}$, Handeng Lv ${ }^{1}$, Di Chen ${ }^{1}$, Guoliang Shen ${ }^{1}$, \\ Kaiqi Wu ${ }^{1}$, Suwei Pan ${ }^{1}$ and Faqing Ye ${ }^{1, *}$ \\ 1 School of Pharmaceutical Sciences, Wenzhou Medical University, Wenzhou 325035, China; \\ zy8428@126.com (Y.Z.); 15868535718@163.com (L.L.); hannoverkalte@163.com (C.H.); \\ lhd19924@163.com (H.L.); 15958709517@163.com (D.C.); shen09427@163.com (G.S.); \\ 18268253895@163.com (K.W.); psw835224635@126.com (S.P.) \\ 2 Department of Forensic Medicine, School of Medicine, Xi'an Jiaotong University, Xi'an 710061, China \\ * Correspondence: yfq664340@163.com; Tel.: +86-577-8668-9369; Fax: +86-577-8668-9369 \\ + These authors contribute equally to this work.
}

Received: 19 October 2017; Accepted: 7 November 2017; Published: 13 November 2017

\begin{abstract}
We designed and synthesized 26 prototype compounds and studied their anti-inflammatory activity and underlying molecular mechanisms. The inhibitory effects of the compounds on the production of nitric oxide (NO), cytokines, inflammatory-related proteins, and mRNAs in lipopolysaccharide (LPS)-stimulated macrophages were determined by the Griess assay, Enzyme linked immunosorbent assay (ELISA), Western blot analysis, and Reverse transcription-Polymerase Chain Reaction (RT-PCR), respectively. Our results indicated that treatment with A2, A6 and B7 significantly inhibited the secretion of NO and inflammatory cytokines in RAW264.7 cells without demonstrable cytotoxicity. It was also found that $\mathbf{A 2}, \mathbf{A} \mathbf{6}$ and $\mathbf{B} 7$ strongly suppressed the expression of inducible nitric oxide synthase (iNOS) and cyclooxygenase enzyme COX-2, and prevented nuclear translocation of nuclear factor $\kappa \mathrm{B}(\mathrm{NF}-\mathrm{kB})$ p 65 by inhibiting the degradation of p50 and I $\mathrm{B} \mathrm{B}$. Furthermore, the phosphorylation of mitogen-activated protein kinase (MAPKs) in LPS-stimulated RAW264.7 cells was significantly inhibited by A2, A6 and B7. These findings suggest that A2, A6 and B7 may operate as an effective anti-inflammatory agent through inhibiting the activation of NF- $\mathrm{kB}$ and MAPK signaling pathways in macrophages. Moreover, rat paw swelling experiments showed that these compounds possess anti-inflammatory activity in vivo, with compound A6 exhibiting similar activities to the reference drug Indomethacin.
\end{abstract}

Keywords: tetrahydrobenzo[4,5]thieno[2,3- $d$ ]pyrimidine; anti-inflammatory; cytotoxicity; paw edema

\section{Introduction}

Activated macrophages play crucial roles in the initiation and maintenance of inflammation. Following activation by inflammatory stimuli such as lipopolysaccharide (LPS), macrophages secrete a number of potent bioactive inflammatory mediators, including nitric oxide (NO), prostaglandins

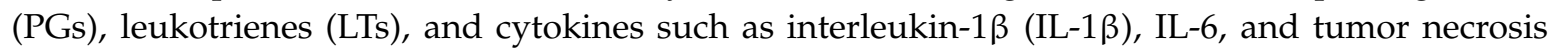
factor $\alpha$ (TNF- $\alpha)$, that contribute to the activation of mitogen-activated protein kinase (MAPK) and nuclear factor $\mathrm{kB}(\mathrm{NF}-\mathrm{kB})$ [1-10]. Of note, as an important inflammatory mediator, the paradoxical role of $\mathrm{NO}$ in the pathogenesis of inflammation generally depends upon concentration [11]. Appropriate levels of NO produced by inducible NO synthase (iNOS) in response to inflammatory stimuli such as interferon- $\gamma$ (IFN- $\gamma$ ), IL-1 $\beta$, and LPS assist in mounting an effective defense against pathogens [12]. However, sustained overproduction of NO by iNOS is believed to be 
detrimental to the host and is associated with the pathogenesis of a variety of inflammatory disorders [13]. Therefore, pharmacological interference with NO production is appreciated as a promising strategy of therapeutic intervention in inflammatory diseases [14]. Conversely, while the major role of housekeeping cyclooxygenase enzyme COX-1 is to regulate the arachidonic acid metabolic pathway [15], the inducible cyclooxygenase COX-2 is responsible for the production of pro-inflammatory prostaglandins $[16,17]$, which makes COX-2 a selected target of anti-inflammatory drugs. Starting from the clinical use of aspirin, diclofenac, and indomethacin as non-steroidal anti-inflammatory drugs (NSAIDs) [18,19], the development of COXIBs [20-22] has provided some relief to patients suffering from a wide spectrum of inflammatory diseases. However, the cardiovascular side effects associated with the use of COXIBs is a limiting factor that has subdued the medicinal applications of this class of anti-inflammatory drugs [23-28], and hence, the search for new anti-inflammatory chemical entities continues.

Previously, during the study of tetrahydrobenzo[4,5]thieno[2,3- $d]$ pyrimidine series of fibroblast growth factor FGFR1 inhibitors, we were intrigued by the findings that compounds such as $\mathbf{4 b}$ (Scheme 1) inhibited the production of TNF- $\alpha$ and IL-6 [29]. In the literature, it is known that compounds with a similar thieno[2,3- $d$ ]pyrimidine scaffold has been reported as anti-inflammatory agents [30,31]. In addition, as a bioisostere of quinazoline, thieno[2,3- $d$ ]pyrimidine has been used extensively for a pharmacophore and synthesis of compounds with diverse biological activities, including anti-tumor [32-38], anti-microbial [33,39], anti-viral [40-42], anti-diabetic [43], anti-anxiolytic [44], and antioxidant [45] activities. We therefore set out to explore the potential anti-inflammatory activity of $\mathbf{4} \mathbf{b}$, the tetrahydrobenzo[4,5]thieno[2,3-d]pyrimidine compound; however, the activity of $\mathbf{4 b}$ has room for improvement, so we attempted to change the amino into carbonyl to obtain the compound A1, possessing hydrogen bond receptor to improve the binding between compounds and inflammatory cytokine. According to preliminary anti-inflammation activity screening, $\mathrm{A} 1$ is superior to $4 \mathbf{b}$ (51.64\% and $49.83 \%$ for anti-IL-6, as well as $50.70 \% 48.23 \%$ for anti-TNF-alpha). Furthermore, we performed further structural modifications to $\mathbf{A} \mathbf{1}$ at $\mathbf{2}$ and $\mathbf{3}$ positions, respectively, to get compounds with better anti-inflammatory activity and to study the underlying molecular mechanisms of this novel class of compounds.

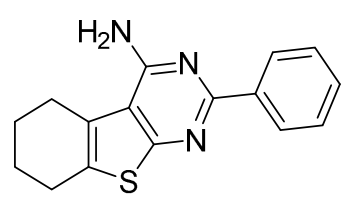

$4 b$

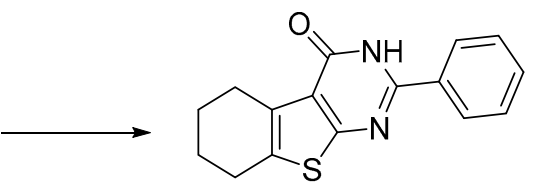

A1

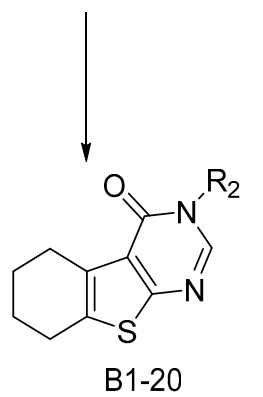

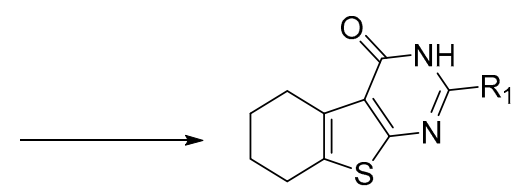

A2-6

Scheme 1. Design of tetrahydrobenzo[4,5]thieno[2,3- $d]$ pyrimidine derivatives.

\section{Results and Discussion}

\subsection{Chemistry}

Based on the structure of template $4 b$, we envisaged that it would be interesting to explore the optimal interaction between the phenyl substituent and its biological target, as well as to exploit any potential hydrogen bonding that could result from the amino group on the pyrimidine ring. 
Thus, we attempted to introduce a carbonyl in place of the amino group, and to modify the 2-, and 3-positions of the tetrahydrobenzo[4,5]thieno[2,3-d]pyrimidine system. The construction of the desired template that features a fused tricyclic heterocycle began from the condensation of cyclohexanone and ethyl cyanoacetate in the presence of elemental sulfur (Scheme 2). The key intermediate $\mathbf{1}$ has functionalities at the 2- and 3-positions of the tetrahydrobenzothiophene ring that allow formation of the pyrimidine ring with different substituents. In one route, reaction of intermediate 1 with aryl or alkyl nitrile generated compounds A1-6 in good yields (Table 1). Alternatively, reaction of $\mathbf{1}$ with triethyl orthoformate in reflux acetic anhydride provided intermediate 2 , which upon treatment with hydrazine hydrate readily cyclized to give compound 3 . The exocyclic amine in $\mathbf{3}$ was then further functionalized to provide a variety of hydrazine imines, B1-20 (Table 2), using selected aldehydes.

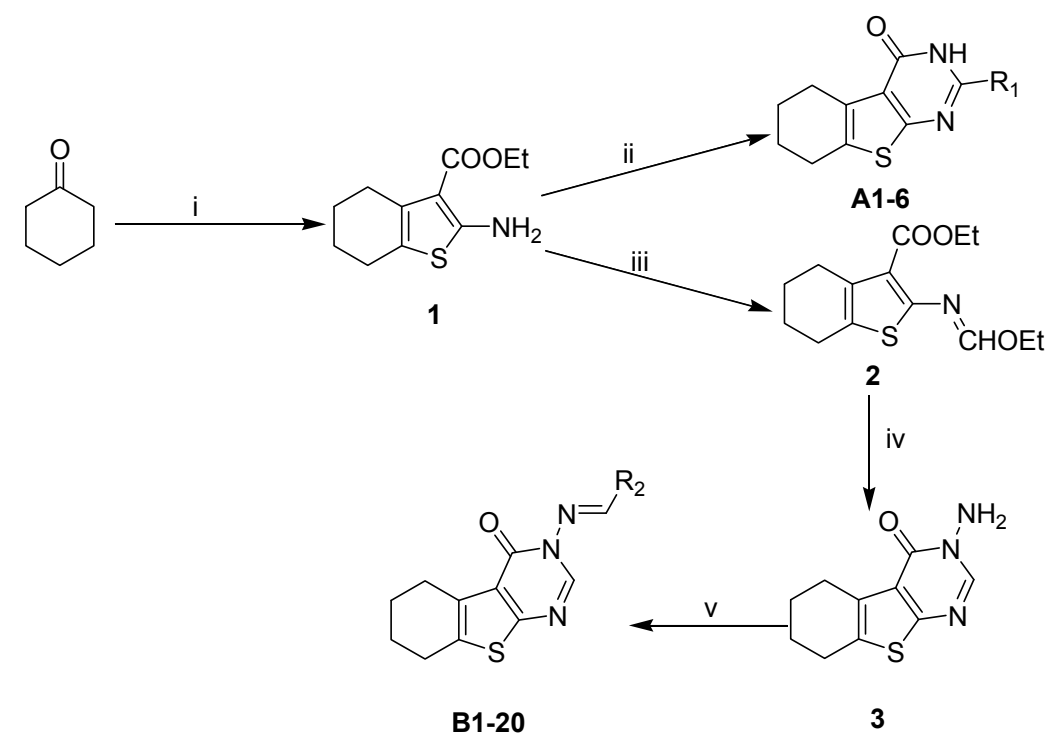

Scheme 2. Synthesis of target compounds. Conditions: (i) $\mathrm{S}, \mathrm{Et}_{2} \mathrm{NH}, \mathrm{EtOH}, \mathrm{NCCH}_{2} \mathrm{COOEt}$; (ii) $\mathrm{R}_{1} \mathrm{CN}$, $\mathrm{HCl}$, dioxane, $\mathrm{EtOH}$; (iii) $\mathrm{Ac}_{2} \mathrm{O}, \mathrm{CH}(\mathrm{OEt})_{3}$; (iv) $\mathrm{NH}_{2} \mathrm{NH}_{2} \cdot \mathrm{H}_{2} \mathrm{O}$; and (v) $\mathrm{R}_{2} \mathrm{CHO}, \mathrm{EtOH}, \mathrm{AcOH}$.

Table 1. Chemical Structures of Target Compounds A1-6.

Compound


Table 2. Chemical Structures of Target Compounds B1-20.

\begin{tabular}{|c|c|c|c|}
\hline Compound & $\mathbf{R}_{\mathbf{2}}$ & Compound & $\mathbf{R}_{2}$ \\
\hline B1 & & B11 & \\
\hline B2 & & B12 & \\
\hline B3 & & B13 & \\
\hline B4 & & B14 & \\
\hline B5 & & B15 & \\
\hline B6 & & B16 & \\
\hline B7 & & B17 & \\
\hline B8 & & B18 & \\
\hline B9 & & B19 & \\
\hline B10 & & B20 & \\
\hline
\end{tabular}




\subsection{Biological Studies}

\subsubsection{Cytotoxicity Assay}

The cytotoxicity of all compounds was evaluated in RAW264.7 cells by MTT assay after $72 \mathrm{~h}$ of treatment. As observed from the cell viability data in Figure 1, the survival rate of all compound treated cells is higher than $80 \%$, indicating that a concentration of up to $160 \mu \mathrm{M}$ was not associated with any significant change in overall cell viability.
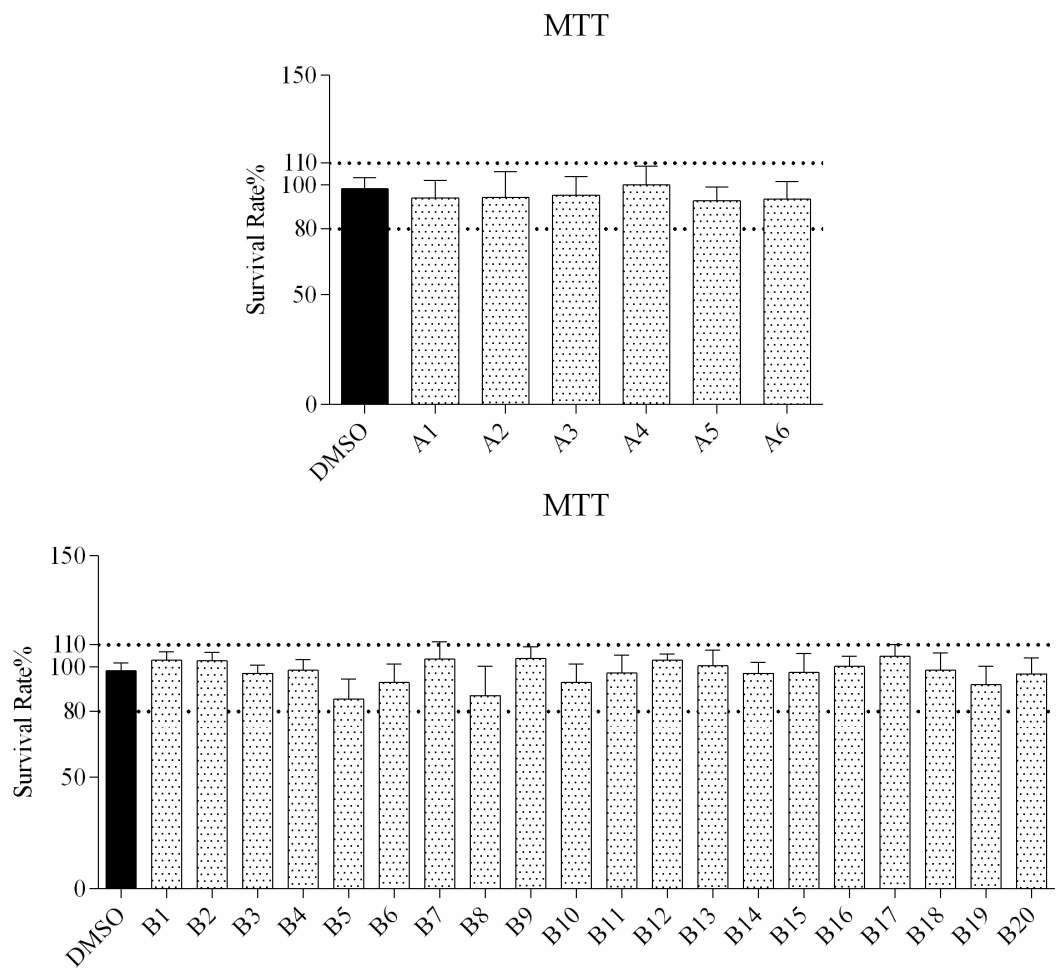

Figure 1. In vitro survival rate of RAW264.7 cells treated with compound A1-6 and B1-20 at $160 \mu \mathrm{M}$.

\subsubsection{Effects of Compound Treatment on Inflammatory Cytokine Secretion}

ELISA was used to evaluate secretion of the cytokines TNF- $\alpha$ and IL-6 in macrophages following compound treatment. As shown in Figures 2 and 3, the secretion of inflammatory cytokines was significantly inhibited by most of the compounds at $10 \mu \mathrm{M}$ concentration. Notably, compounds A2, A6, and B7 most strongly suppressed secretion of TNF- $\alpha$ and IL-6, and were selected for further characterization.

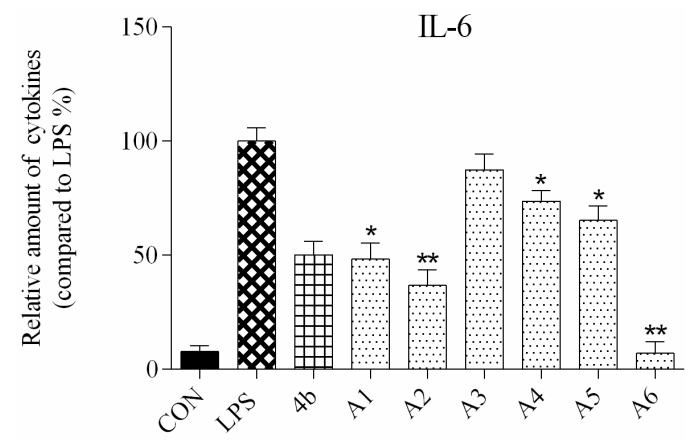

Figure 2. Cont. 


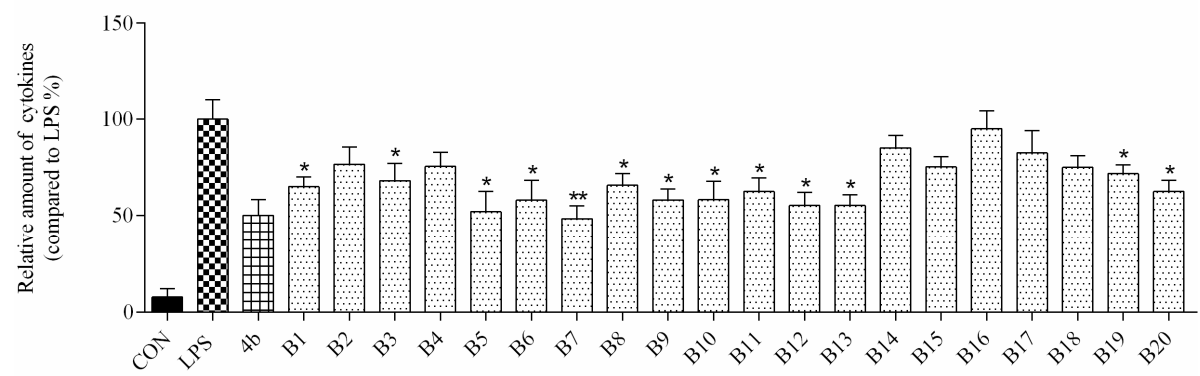

Figure 2. Relative levels of cytokine IL-6 in macrophages after treatment with compounds A1-6 and B1-20 at $10 \mu \mathrm{M}$ concentration as compared to LPS group and indomethacin group $\left({ }^{*}: p<0.05 ;{ }^{* *}: p<0.01\right)$.
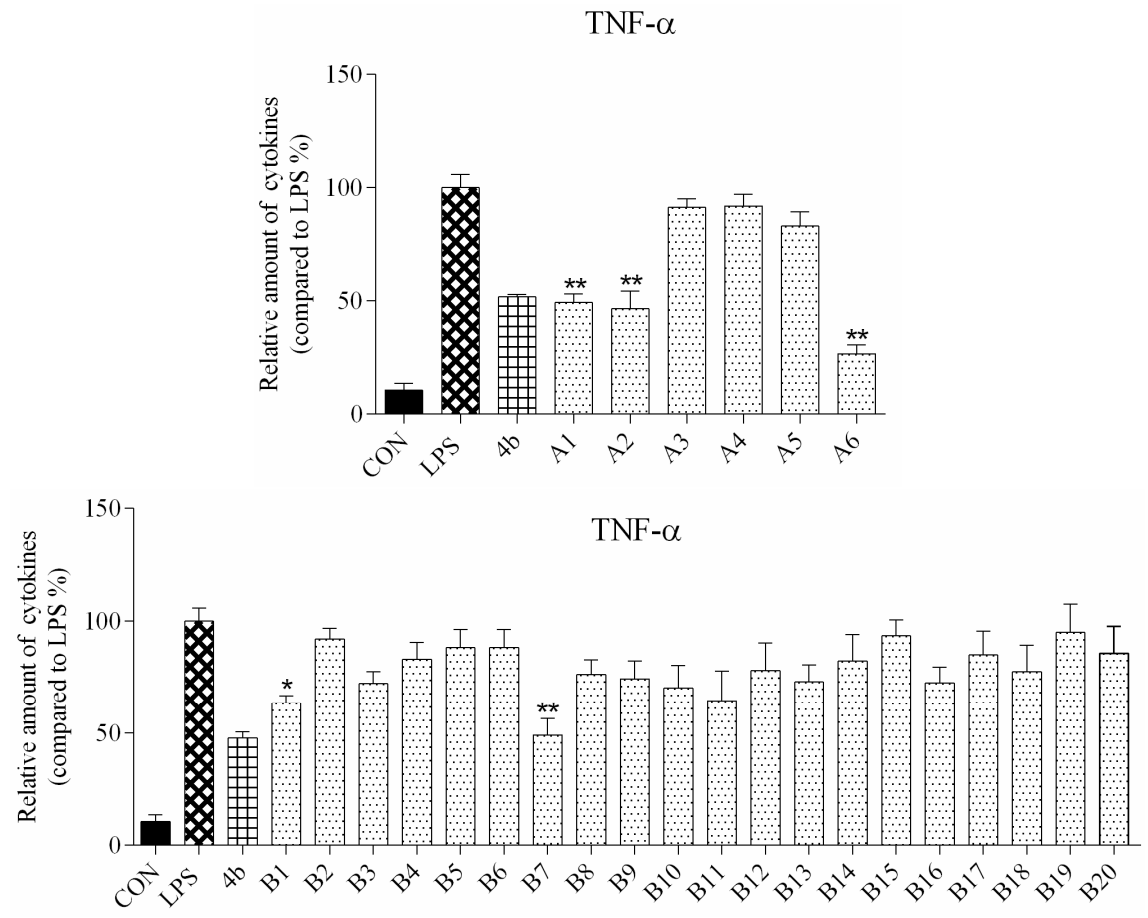

Figure 3. Relative levels of cytokine TNF- $\alpha$ in macrophages after treatment with compounds A1-6 and B1-20 at $10 \mu \mathrm{M}$ concentration as compared to LPS group and indomethacin group $\left({ }^{*}: p<0.05 ;{ }^{* *}: p<0.01\right)$.

\subsubsection{Preliminary Structure Activity Relationship (SAR)}

As shown in Figure 2, all compounds had significantly low cytotoxicity. As shown in Figures 3 and 4 , most of the tetrahydrobenzo[4,5]thieno[2,3- $d$ ]pyrimidine derivatives were found to exhibit comparable anti-IL-6 and anti-TNF-alpha activity with $\mathbf{4 b}$, especially A2, A6, and B7, which showed great anti-inflammation activity. Replacing with chloromethyl group and pyridine at 2 position obtained better activity than $4 \mathrm{~b}$ and other substitutes; the two groups, as electron donating groups, can improve the anti-inflammation activity. Moreover, replacing with naphthyl group at 3 position obtained the better activity for compound B7; naphthyl group can offer multi- $\pi-\pi$ conjugated system, which contributes to binding with inflammatory cytokine obtain better inhibitory effection. 

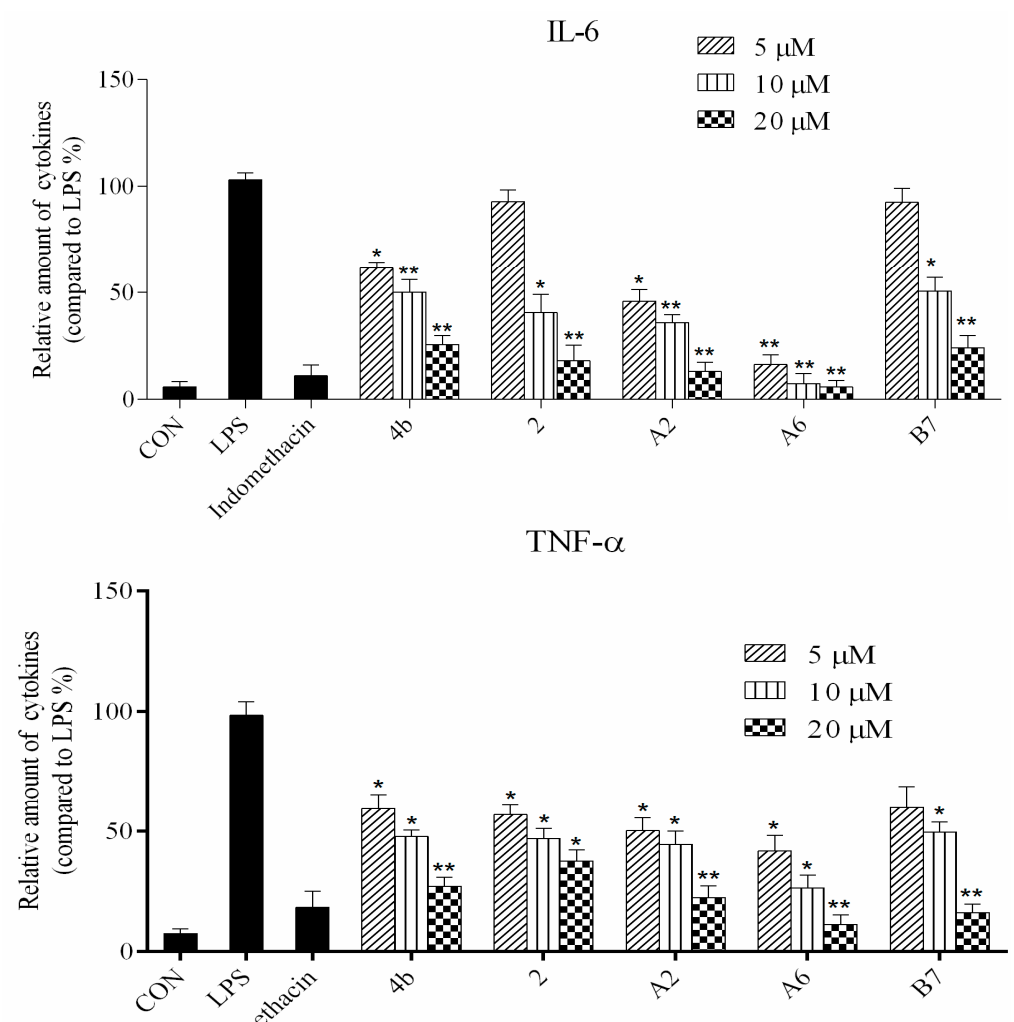

IL- $1 \beta$

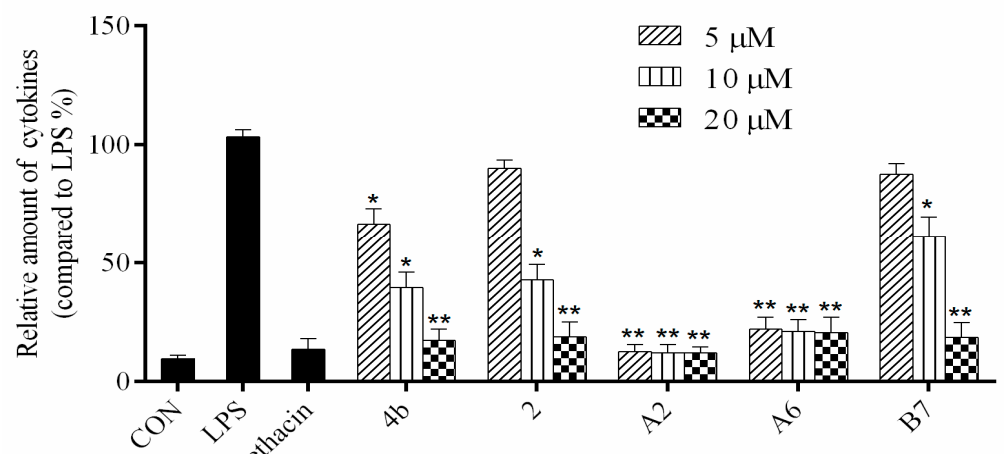

PGE2

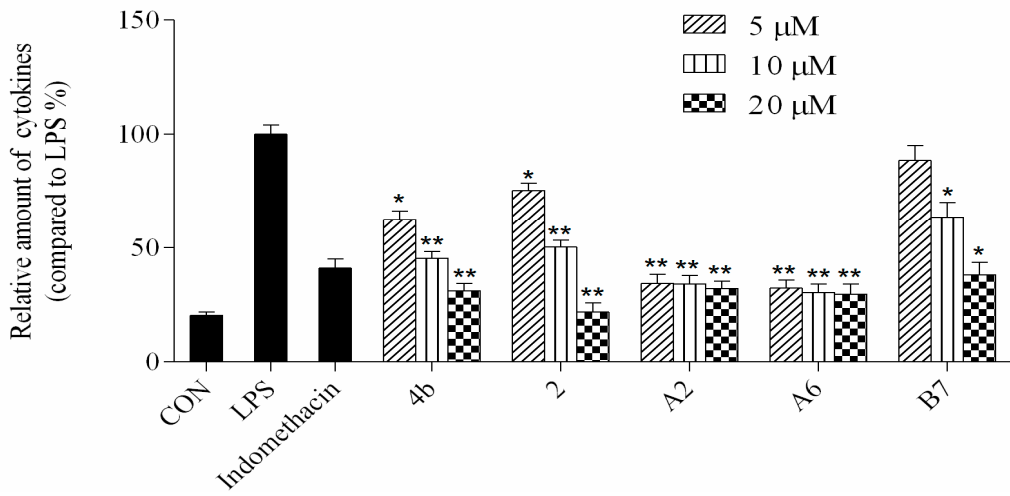

Figure 4. Compounds $4 \mathbf{b}, \mathbf{2}, \mathbf{A} \mathbf{2}, \mathbf{A} \mathbf{6}$, and $\mathbf{B} 7$ reduced the production of IL- 6 , TNF- $\alpha$, IL-1 $\beta$, and PGE2 at concentrations of $5 \mu \mathrm{M}, 10 \mu \mathrm{M}$, and $20 \mu \mathrm{M}\left({ }^{*}: p<0.05 ; * *: p<0.01\right)$. 


\subsubsection{Dose Response Effects of Compound A2, A6, B7 on Inflammatory Cytokine Secretion}

ELISA was used to evaluate cytokine TNF- $\alpha$, IL-6, IL-1 $\beta$, and PGE2 secretion in macrophages following treatment with compounds 4b, 2, A2, A6, and B7. As shown in Figure 4, the secretion of four inflammatory cytokines was significantly inhibited by compounds 4b, 2, A2, A6, and B7 in a dose-dependent manner. Notably, treatment with A2 and A6 strongly suppressed cytokine secretion more significantly than compounds $\mathbf{4 b}, \mathbf{2}$, and B7. Moreover, compound A6 inhibited the production of four inflammatory cytokines with similar activity to the positive control indomethacin at $10 \mu \mathrm{M}$.

\subsubsection{Inhibitory Effects of Compounds A2, A6, B7 on NO Production}

It has been well established that $\mathrm{NO}$ production is correlated with various inflammatory diseases. We investigated the suppressive effects of compounds 4b, 2, A2, A6, and B7 on NO levels in macrophages stimulated with LPS. The supernatant was treated with a range of concentrations (1-100 $\mu \mathrm{M})$ of compounds for $1 \mathrm{~h}$ followed by stimulation with LPS for $24 \mathrm{~h}$ and $96 \mathrm{~h}$, and NO production was measured using Griess reagent. It was found that compounds 4b, 2, A2, A6, and B7 dramatically inhibited the release of $\mathrm{NO}$ in a dose-dependent manner following LPS stimulation (Figure 5). The effects at $24 \mathrm{~h}$ were more significant compared to $96 \mathrm{~h}$. In particular, compound $\mathbf{A 6}$ displayed higher inhibitory activity when compared with the positive control indomethacin at $1 \mu \mathrm{M}$.

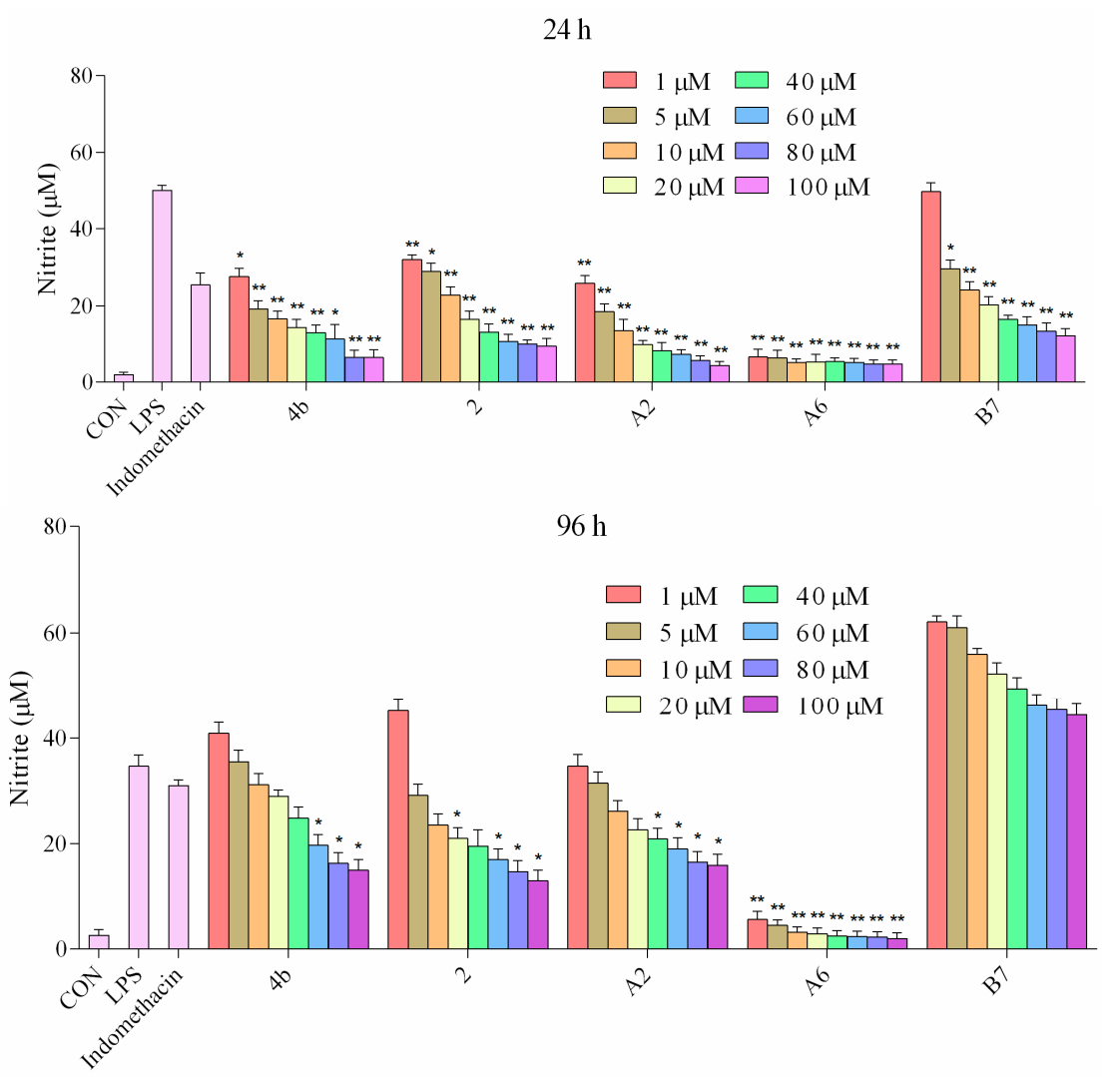

Figure 5. Production of $\mathrm{NO}$ in macrophages following treatment with different concentrations of $4 \mathbf{b}, \mathbf{2}$, A2, A6, B7, and $1 \mu \mathrm{M}$ indomethacin for 24 and $96 \mathrm{~h}\left({ }^{*}: p<0.05 ; * *: p<0.01\right)$.

\subsubsection{Effects of Compounds A2, A6, B7 on iNOS and COX-2 Expression Levels}

The effects of compound A2, A6, and B7 treatment on mRNA and protein expression of iNOS and COX-2 in RAW264.7 cells were investigated by RT-PCR analysis and Western blotting. As shown in Figure 6, treatment with A2, A6, and B7 markedly reduced iNOS and COX-2 mRNA levels, with 
higher inhibitory effects compared to indomethacin. Moreover, as shown in Figure 7, compounds A2, A6, and B7 significantly decreased the protein levels of iNOS and COX-2.
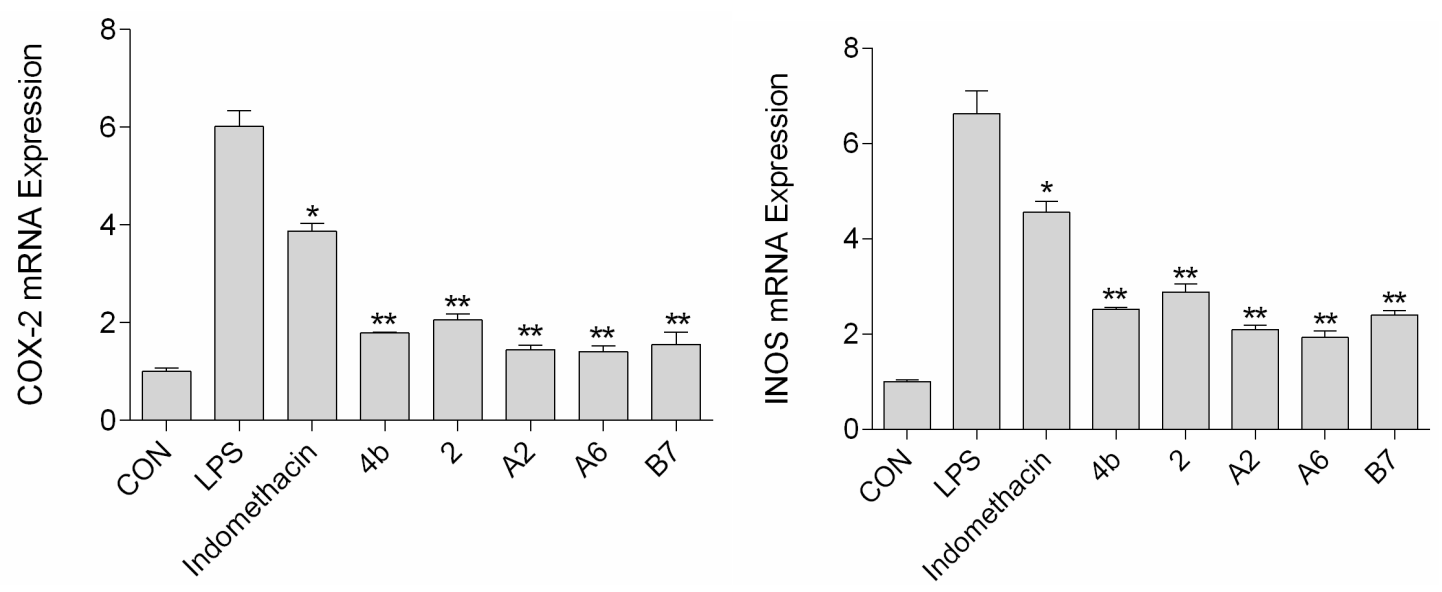

Figure 6. The expression of COX-2 and iNOS mRNA after treatment with $10 \mu \mathrm{M}$ compound $\mathbf{4 b}, \mathbf{2}, \mathbf{A 2}$, A6, B7, or indomethacin $\left({ }^{*}: p<0.05 ;{ }^{* *}: p<0.01\right)$.

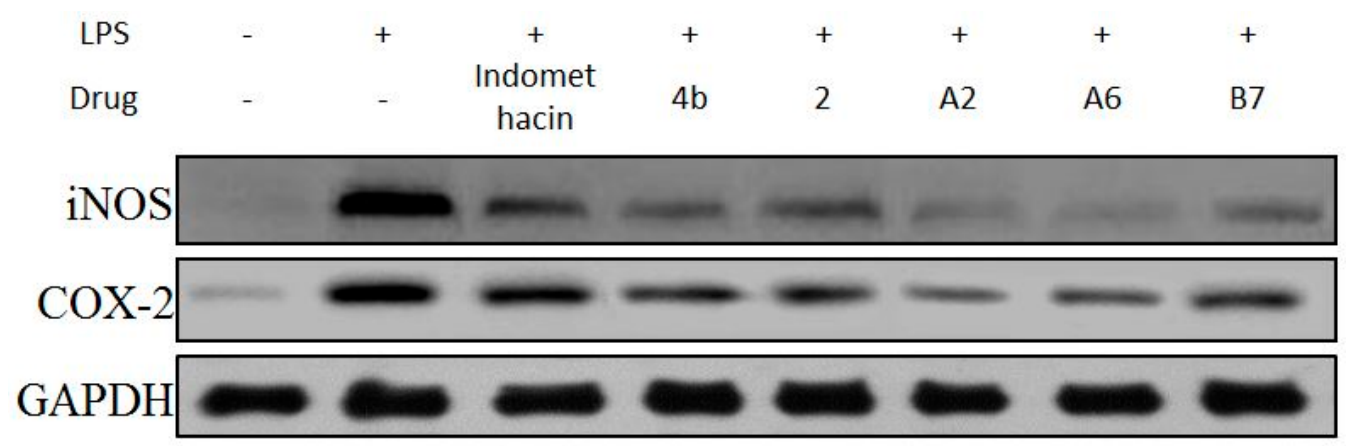

Figure 7. Immunoblotting of cellular proteins COX-2 and iNOS expression in RAW264.7 cells treated with $10 \mu \mathrm{M}$ compounds $\mathbf{4 b}, \mathbf{2}, \mathbf{A} \mathbf{2}, \mathbf{A 6}$, B7, or indomethacin. GAPDH was used as a loading control.

\subsubsection{Effects of Compounds A2, A6, B7 on Cellular NF- $k B$ p65 Translocation}

Transcription factor NF- $\mathrm{kB}$ signaling is pivotal in the induction of inflammatory responses. A key event involves I $\mathrm{kB}$ (inhibitors of NF-kB) phosphorylation and degradation that leads to the release of NF- $\kappa \mathrm{B}$ p65 subunit from the cytoplasm, followed by translocation to the nucleus, where it binds to target promoters, and activates transcription of inflammatory genes including TNF- $\alpha$, IL- 6 , IL-1 $\beta$, IL-12, and COX-2. The effects of compound A2, A6, B7 on NF-kB p65 subunit nuclear translocation was determined in an immunofluorescence assay. As shown in Figure 8, LPS induction increased NF- $\mathrm{BB}$ p65 nuclear translocation (green dots in blue nucleus), while, in A2, A6, and B7 pretreated macrophages, LPS-induced nuclear p65 decreased, suggesting that A2, A6, and B7 inhibited p65 translocation from cytoplasm to nuclei. The results suggest that the anti-inflammatory activity of compounds A2, A6, and B7 may be associated with inhibitory effects on NF-kB activation. 

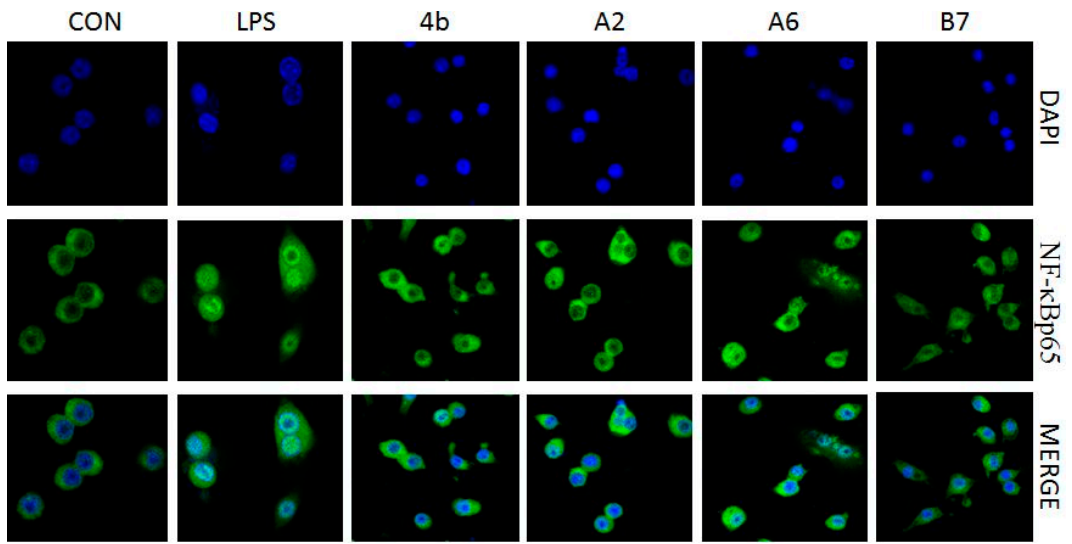

Figure 8. Immunofluorescence of NF-kB p65 in RAW264.7 cells exposed to LPS $(100 \mathrm{ng} / \mathrm{mL})$ with or without compound $4 \mathbf{b}, \mathbf{A 2}, \mathbf{A 6}$, and $\mathbf{B} 7(10 \mu \mathrm{M})$.

\subsubsection{Effects of Compounds A2, A6, B7 on MAPKs Phosphorylation in LPS-Stimulated} RAW264.7 Cells

In mitogen-activated protein kinase (MAPK) pathways, ERK1/2, p38, and JNK protein kinases are essential regulators of the inflammatory response [46]. The effects of compound A2, A6, B7 on the activation of MAPKs were determined by Western blot analysis using specific antibodies for the corresponding phosphorylated forms. As displayed in Figure 9, compound A2, A6, and B7 treatment markedly inhibited the phosphorylation of ERK1/2, p38, and JNK compared to indomethacin treatment, with compound $\mathbf{A 6}$ exhibiting the most significant inhibitory effect.

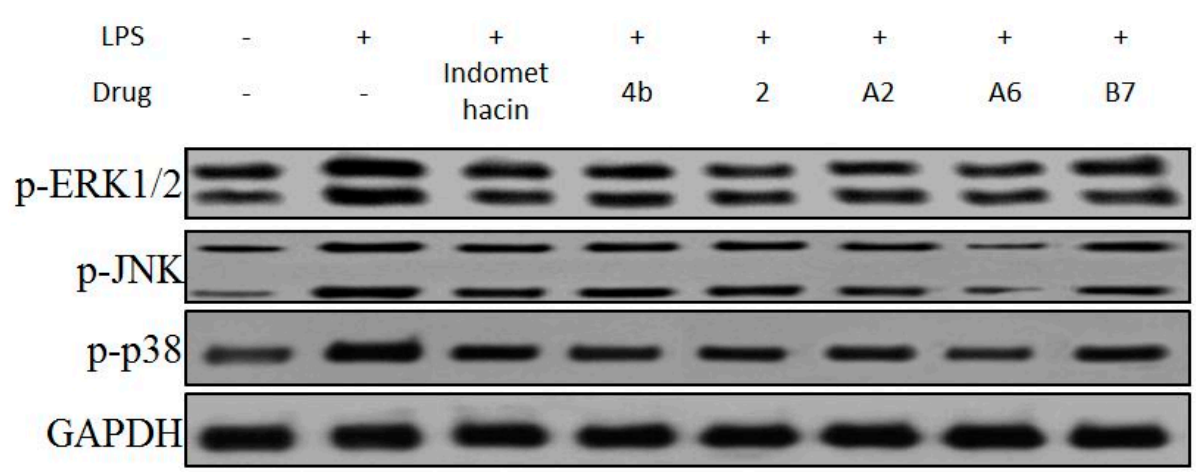

Figure 9. Immunoblotting of p-ERK1/2, p-p38, and p-JNK of MAPK signaling pathway in RAW264.7 cells treated with $10 \mu \mathrm{M}$ compound $\mathbf{4 b}, \mathbf{2}, \mathbf{A} \mathbf{2}, \mathbf{A} \mathbf{6}$, and $\mathbf{B} 7$, or indomethacin. GAPDH was used as a loading control.

\subsubsection{Effects of Compounds A2, A6, B7 Treatment on NF- $\kappa B$ Activation in LPS-Stimulated RAW264.7 Cells}

Due to the importance of NF- $\kappa \mathrm{B}$ activation in the regulation of the inflammatory response, the effects of compound $\mathbf{A 2}$, A6, and $\mathbf{B} 7$ treatment on LPS-induced changes in the levels of p50 and I $\kappa \mathbf{B} \alpha$ were determined (Figure 10). The results showed that, similar to indomethacin, treatment with A2, A6, and $\mathbf{B} 7$ effectively blocked LPS-induced activation of NF- $\kappa$ B in macrophages, with A6 exhibiting the most significant inhibitory effect. 


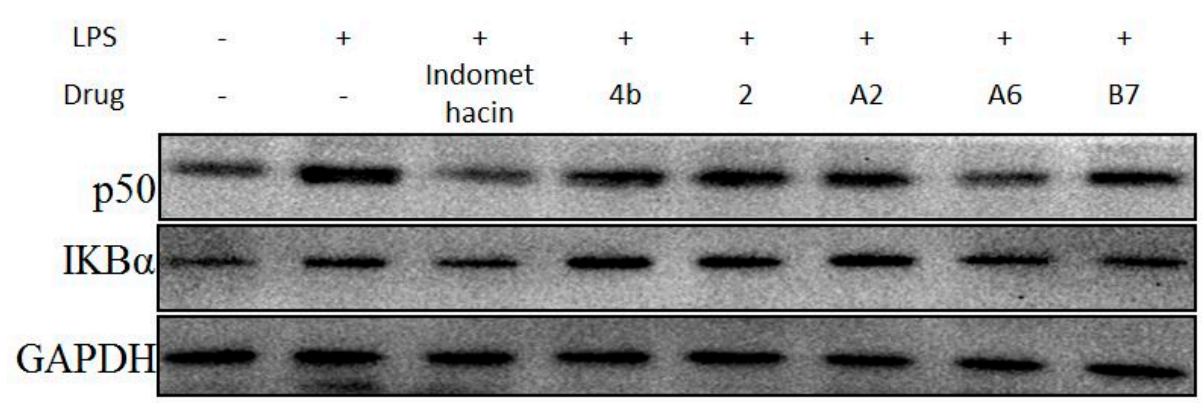

Figure 10. Immunoblotting of $\mathrm{p} 50$ and IKB $\alpha$ of NF- $\kappa \mathrm{B}$ signaling pathway in RAW264.7 cells treated with $10 \mu \mathrm{M}$ compound $\mathbf{4 b}$, 2, A2, A6, B7, or indomethacin. GAPDH was used as a loading control.

\subsubsection{Anti-Inflammatory Activity of A2, A6, and $\mathbf{B} 7$ in Carrageenan-Induced Rat Paw Edema}

In the rat paw edema model, both the compound group and positive control group showed reduction of carrageenan-induced rat paw edema at varying levels (Figure 11). Compounds A2, A6, and $\mathbf{B} 7$ displayed improved activity compared to $\mathbf{4 b}$, with $\mathbf{A 6}$ exhibiting the highest in vivo activity among the three new analogs, comparable to celecoxib and indomethacin. Based on all results, A6 can serve as a lead compound for further studies.

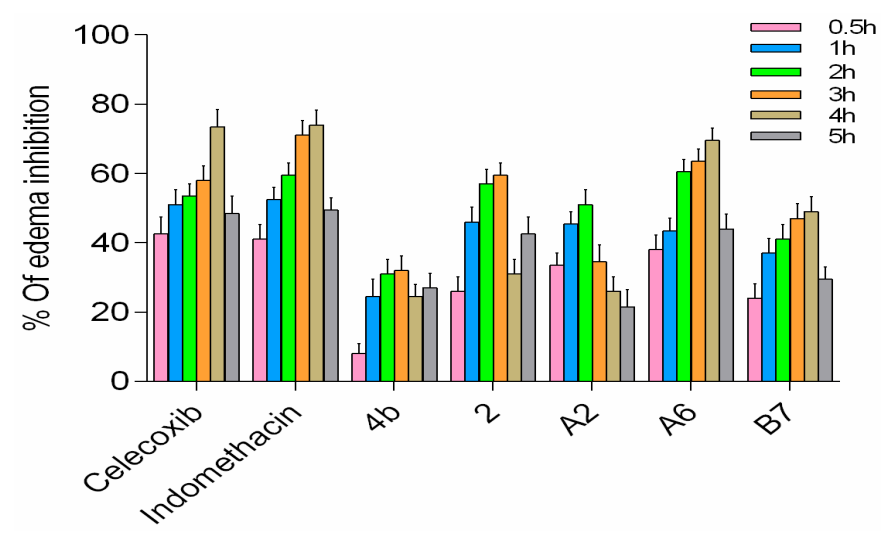

Figure 11. In vivo anti-inflammatory activity of A2, A6, and $\mathbf{B} 7$ against carrageenan-induced rat paw edema.

\section{Materials and Methods}

\subsection{General}

Melting points were determined in SGWX-4 microscopic melting point meter and are uncorrected. ${ }^{1} \mathrm{H}$ - and ${ }^{13} \mathrm{C}-\mathrm{NMR}$ spectra were recorded on Bruker $600 \mathrm{MHz}$ NMR spectrometer, using $\mathrm{CDCl}_{3}$ or DMSO- $\mathrm{d}_{6}$ as solvents. Chemical shifts are expressed in ppm with TMS as internal reference. $J$ values are provided in hertz. Mass spectra were recorded on Bruker micrOTOF QII mass spectrometer. Reactions were monitored by thin layer chromatography (TLC) on glass plates coated with silica gel GF-254. Column chromatography was performed with 200-300 mesh silica gel.

\subsubsection{General Procedure for the Synthesis of 1}

To a round bottom flask, $3.2 \mathrm{~g}$ sulfur was added, along with $11 \mathrm{~mL}$ cyanoacetic acid ethyl ester, $10 \mathrm{~mL}$ cyclohexanone, and $20 \mathrm{~mL}$ ethanol at room temperature. The mixture was stirred for $10 \mathrm{~min}$, then $8 \mathrm{~mL}$ diethylamine was added and the reaction was stirred at room temperature for $12 \mathrm{~h}$. The reaction mixture was suction-filtered and the cake was rinsed with water:ethanol $=1: 1$ three times, and the filtrate was dried to afford a light yellow solid. 


\subsubsection{General Procedure for the Synthesis of A1-6}

One gram of intermediate $\mathbf{1}$ and $\mathbf{2}$ molar equivalents of an appropriately substituted nitrile were dissolved in $15 \mathrm{~mL}$ dioxane, and the mixture was stirred at $80^{\circ} \mathrm{C}$ for $10 \mathrm{~min}$, then $20 \mathrm{~mL}$ hydrochloric acid was added. The reaction continued for $6 \mathrm{~h}$, and was cooled to ambient temperature, poured into ice water, and adjusted to slightly basic using ammonia. The precipitate was suction-filtered to afford the crude product. Silica gel column chromatography using 3:1 petroleum ether:ethyl acetate as eluent yielded compounds A1-6.

\subsubsection{General Procedure for the Synthesis of 2 and 3}

One gram of intermediate $\mathbf{1}$ and $0.1 \mathrm{~g}$ of acetic anhydride were dissolved in triethoxymethane, and the reaction was refluxed for $6 \mathrm{~h}$. The reaction was cooled to ambient temperature and concentrated under vacuum to give a red semi-solid. Recrystallization of the crude product using ethanol $/ n$-hexane afforded intermediate 2 . Intermediate 2 was added to hydrazine hydrate in a molar ratio of 1:1.5, and the neat reaction was refluxed overnight, and monitored by TLC until completion. TLC analysis was performed using 1:1 petroleum ether:ethyl acetate, and the retention factor of target materials are $0.4-0.6$. The reaction mixture was concentrated under vacuum, and the crude product was recrystallized using 1:1 ethanol $/ n$-hexane to afford Intermediates 3 .

\subsubsection{General Procedure for the Synthesis of B1-20}

To a round bottom flask, $1.12 \mathrm{~g}$ of intermediate 3 was added, along with $6 \mathrm{~mL}$ anhydrous ethanol, and appropriately substituted aldehyde. The reaction was warmed to $50{ }^{\circ} \mathrm{C}$ and $2 \mathrm{~mL}$ acetic acid was added. The reaction was refluxed for $6 \mathrm{~h}$, and then the response process was monitored by TLC analysis using 1:2 petroleum ether:ethyl acetate, and the retention factor of target compounds are 0.3-0.5. The reaction mixture was cooled to room temperature and was filtered. The product was purified by crystallization with ethanol to afford compounds B1-20.

2-Phenyl-5,6,7,8-tetrahydrobenzo[4,5]thieno[2,3-d]pyrimidin-4(3H)-one (A1). Yield 79\%; m.p. 210-212 ${ }^{\circ} \mathrm{C}$; ${ }^{1} \mathrm{H}-\mathrm{NMR}\left(600 \mathrm{MHz}, \mathrm{CDCl}_{3}\right): \delta 8.40\left(\mathrm{~d}, J=\mathrm{C}-\mathrm{NMR} 7.8 \mathrm{~Hz}, 2 \mathrm{H}, 2^{\prime}, 6^{\prime}-\mathrm{Ph}-\mathrm{H}\right), 7.44\left(\mathrm{dt}, J_{1}=7.8 \mathrm{~Hz}\right.$, $\left.J_{2}=6.0 \mathrm{~Hz}, 3 \mathrm{H}, 3^{\prime}, 4^{\prime}, 5^{\prime}-\mathrm{Ph}-\mathrm{H}\right), 5.34(\mathrm{~s}, 1 \mathrm{H},-\mathrm{NH}), 2.95(\mathrm{t}, J=5.4 \mathrm{~Hz}, 2 \mathrm{H}, 8$-Tetrahydrophenyl-H), $2.83(\mathrm{t}$, $J=4.8 \mathrm{~Hz}, 2 \mathrm{H}, 5$-Tetrahydrophenyl-H), 1.96 (m, 4H, 6,7-Tetrahydrophenyl-H); ${ }^{13} \mathrm{C}-\mathrm{NMR}(151 \mathrm{MHz}$, $\left.\mathrm{CDCl}_{3}\right) \delta 163.37,158.69,145.76,137.40,134.71,131.18,129.18,127.05,113.52,25.73,25.28,22.57,22.51$; ESI-MS $m / z: 283.2[\mathrm{M}+1]^{+}$, calculated for $\mathrm{C}_{16} \mathrm{H}_{14} \mathrm{~N}_{2} \mathrm{OS}$ : 282.4.

2-(Pyridin-2-yl)-5,6,7,8-tetrahydrobenzo[4,5]thieno[2,3-d]pyrimidin-4(3H)-one (A2). Yield 80\%; m.p. 201-203 ${ }^{\circ} \mathrm{C} ;{ }^{1} \mathrm{H}-\mathrm{NMR}\left(600 \mathrm{MHz}, \mathrm{CDCl}_{3}\right) \delta 8.82(\mathrm{~d}, J=3.6 \mathrm{~Hz}, 1 \mathrm{H}$, Pyridin- $\mathrm{H}), 8.50(\mathrm{~d}, J=7.8 \mathrm{~Hz}$, 1H, Pyridin-H), $7.84(\mathrm{t}, J=7.8 \mathrm{~Hz}, 1 \mathrm{H}$, Pyridin-H), $7.43(\mathrm{~m}, 1 \mathrm{H}$, Pyridin- $\mathrm{H}), 5.85(\mathrm{~s}, 1 \mathrm{H},-\mathrm{NH}), 2.98(\mathrm{t}$, $J=12.6 \mathrm{~Hz}, 2 \mathrm{H}, 8$-Tetrahydrophenyl-H), $2.85(\mathrm{t}, J=5.4 \mathrm{~Hz}, 2 \mathrm{H}, 5$-Tetrahydrophenyl-H), $1.95(\mathrm{~m}, 4 \mathrm{H}$, 6,7-Tetrahydrophenyl-H); ${ }^{13} \mathrm{C}-\mathrm{NMR}\left(151 \mathrm{MHz}, \mathrm{CDCl}_{3}\right) \delta 163.58,158.08,149.00,148.72,148.21,137.61$, $134.92,132.26,126.06,123.40,121.90,25.77,25.51,23.11,22.38$. ESI-MS $m / z: 284.2[\mathrm{M}+1]^{+}$, calculated for $\mathrm{C}_{15} \mathrm{H}_{13} \mathrm{~N}_{3} \mathrm{OS}: 283.4$.

2-(Pyrimidin-2-yl)-5,6,7,8-tetrahydrobenzo[4,5]thieno[2,3-d]pyrimidin-4(3H)-one (A3). Yield 82\%; m.p. 220-221 ${ }^{\circ} \mathrm{C} .{ }^{1} \mathrm{H}-\mathrm{NMR}\left(600 \mathrm{MHz}, \mathrm{CDCl}_{3}\right) \delta 10.78(\mathrm{~s}, 1 \mathrm{H},-\mathrm{NH}), 8.96\left(\mathrm{~d}, J=4.8 \mathrm{~Hz}, 2 \mathrm{H}, 4^{\prime}, 6^{\prime}-\right.$ Pyrimidin-H), $7.47(\mathrm{t}, J=4.8 \mathrm{~Hz}, 1 \mathrm{H}, 5$-Pyrimidin-H), $3.09(\mathrm{t}, J=5.4 \mathrm{~Hz}, 2 \mathrm{H}, 8$-Tetrahydrophenyl-H), $2.84(\mathrm{t}, J=5.4 \mathrm{~Hz}$, $2 \mathrm{H}, 5$-Tetrahydrophenyl-H), 1.95 (m, 4H, 6,7-Tetrahydrophenyl-H); ${ }^{13} \mathrm{C}-\mathrm{NMR}\left(151 \mathrm{MHz}, \mathrm{CDCl}_{3}\right) \delta$ 167.76, 162.90, 158.24, 158.08, 156.48, 136.88, 125.73, 121.00, 116.32, 26.22, 25.78, 22.65, 22.61; ESI-MS $m / z: 285.2[\mathrm{M}+1]^{+}$, calculated for $\mathrm{C}_{14} \mathrm{H}_{12} \mathrm{~N}_{4} \mathrm{OS}: 284.3$.

2-(4-Hydroxyphenyl)-5,6,7,8-tetrahydrobenzo[4,5]thieno[2,3-d]pyrimidin-4(3H)-one (A4). Yield 64\%; m.p. > $250{ }^{\circ} \mathrm{C} .{ }^{1} \mathrm{H}-\mathrm{NMR}\left(600 \mathrm{MHz}, \mathrm{DMSO}-d_{6}\right) \delta 12.21(\mathrm{~s}, 1 \mathrm{H},-\mathrm{OH}), 10.28(\mathrm{~s}, 1 \mathrm{H},-\mathrm{NH}), 7.98(\mathrm{~d}, J=9.0 \mathrm{~Hz}, 2 \mathrm{H}$, $\left.2^{\prime}, 6^{\prime}-\mathrm{Ph}-\mathrm{H}\right), 6.86$ (d, J = 9.0 Hz, 2H, 3', 5'-Ph-H), 2.88 (t, J = 6.0 Hz, 2H, 8-Tetrahydrophenyl-H), 2.71 (t, $J=6.0 \mathrm{~Hz}, 2 \mathrm{H}, 5$-Tetrahydrophenyl-H), 1.77 (m, 4H, 6,7-Tetrahydrophenyl-H); ${ }^{13} \mathrm{C}-\mathrm{NMR}(151 \mathrm{MHz}$, 
DMSO- $\left.d_{6}\right) \delta 163.34,158.67,157.96,145.73,137.40,130.72,127.54,127.33,116.47,114.64,26.07,25.69$, 22.71, 22.68; ESI-MS $m / z: 298.9[\mathrm{M}+1]^{+}$, calculated for $\mathrm{C}_{16} \mathrm{H}_{14} \mathrm{~N}_{2} \mathrm{O}_{2} \mathrm{~S}: 298.3$.

2-(4-Aminophenyl)-5,6,7,8-tetrahydrobenzo[4,5]thieno[2,3-d]pyrimidin-4(3H)-one (A5). Yield 66\%; m.p. $>250{ }^{\circ} \mathrm{C} .{ }^{1} \mathrm{H}-\mathrm{NMR}\left(600 \mathrm{MHz}, \mathrm{DMSO}-d_{6}\right) \delta 8.03\left(\mathrm{~d}, J=9.0 \mathrm{~Hz}, 2 \mathrm{H}, 2^{\prime}, 6^{\prime}-\mathrm{Ph}-\mathrm{H}\right), 6.82(\mathrm{~s}, 1 \mathrm{H},-\mathrm{NH})$, $6.59\left(\mathrm{~m}, 4 \mathrm{H}, 3^{\prime}, 5^{\prime}-\mathrm{Ph}-\mathrm{H}+\mathrm{NH}_{2}\right), 2.88(\mathrm{t}, 2 \mathrm{H}, J=6.0 \mathrm{~Hz}, 8$-Tetrahydrophenyl-H), $2.71(\mathrm{t}, 2 \mathrm{H}, J=6.0 \mathrm{~Hz}$, 5-Tetrahydrophenyl-H), 1.80 (m, 4H, 6,7-Tetrahydrophenyl-H); ${ }^{13} \mathrm{C}-\mathrm{NMR}$ (151 MHz, DMSO- $d_{6}$ ) 8166.64 , 158.77, 157.96, 150.71, 131.40, 130.02, 129.17, 127.04, 125.03, 113.42, 112.84, 26.23, 25.78, 22.65, 22.61; ESI-MS $m / z: 298.2[\mathrm{M}+1]^{+}$, calculated for $\mathrm{C}_{16} \mathrm{H}_{15} \mathrm{~N}_{3} \mathrm{OS}: 297.4$.

2-(Chloromethyl)-5,6,7,8-tetrahydrobenzo[4,5]thieno[2,3-d]pyrimidin-4(3H)-one (A6). Yield 79\%; m.p. 234-236 ${ }^{\circ} \mathrm{C} .{ }^{1} \mathrm{H}-\mathrm{NMR}\left(600 \mathrm{MHz}\right.$, DMSO- $\left.d_{6}\right) \delta 4.51\left(\mathrm{~s}, 2 \mathrm{H}, 2-\mathrm{CH}_{2} \mathrm{Cl}\right), 2.84(\mathrm{t}, J=5.4 \mathrm{~Hz}$, $2 \mathrm{H}, 8$-Tetrahydrophenyl-H), $2.72(\mathrm{t}, J=4.8 \mathrm{~Hz}, 2 \mathrm{H}$, 5-Tetrahydrophenyl-H), $1.75(\mathrm{~m}, 4 \mathrm{H}$, 6,7-Tetrahydrophenyl-H); ${ }^{13} \mathrm{C}-\mathrm{NMR}\left(151 \mathrm{MHz}, \mathrm{DMSO}-d_{6}\right) \delta 162.26,158.53,152.16,133.74,131.14$, 121.86, 42.86, 25.44, 24.75, 22.66, 21.94. ESI-MS m/z: $254.8[\mathrm{M}+1]^{+}$, calculated for $\mathrm{C}_{11} \mathrm{H}_{11} \mathrm{ClN}_{2} \mathrm{OS}: 254.7$.

(E)-3-(Benzylideneamino)-5,6,7,8-tetrahydrobenzo[4,5]thieno[2,3-d]pyrimidin-4(3H)-one (B1). Yield 83\%; m.p. 216-218 ${ }^{\circ} \mathrm{C} .{ }^{1} \mathrm{H}-\mathrm{NMR}\left(600 \mathrm{MHz}, \mathrm{CDCl}_{3}\right) \delta 9.67$ (s, 1H, N=CH-Ph), 8.19 (s, 1H, 2-pyrimidin-H), $7.89\left(\mathrm{dd}, J_{1}=7.8 \mathrm{~Hz}, J_{2}=1.8 \mathrm{~Hz}, 1 \mathrm{H}, \mathrm{Ph}-\mathrm{H}\right), 7.36(\mathrm{~m}, 1 \mathrm{H}, \mathrm{Ph}-\mathrm{H}), 7.09(\mathrm{t}, J=7.2 \mathrm{~Hz}, 1 \mathrm{H}, \mathrm{Ph}-\mathrm{H}), 6.95$ $(\mathrm{d}, J=8.4 \mathrm{~Hz}, 1 \mathrm{H}, \mathrm{Ph}-\mathrm{H}), 3.04(\mathrm{t}, J=6.0 \mathrm{~Hz}, 2 \mathrm{H}, 8$-Tetrahydrophenyl-H), $2.77(\mathrm{t}, J=6.0 \mathrm{~Hz}, 2 \mathrm{H}$, 5-Tetrahydrophenyl-H), 1.91 (m, 4H, 6,7-Tetrahydrophenyl-H); ${ }^{13} \mathrm{C}-\mathrm{NMR}\left(151 \mathrm{MHz}, \mathrm{CDCl}_{3}\right) \delta 161.39$, 160.58, 159.15, 156.69, 147.36, 134.57, 134.13, 132.30, 127.01, 123.49, 120.07, 119.99, 115.23, 25.87, 25.46, 23.00, 22.40. ESI-MS $m / z: 310.2[\mathrm{M}+1]^{+}$, calculated for $\mathrm{C}_{17} \mathrm{H}_{15} \mathrm{~N}_{3} \mathrm{OS}:$ 309.4.

(E)-3-((2-Methoxybenzylidene)amino)-5,6,7,8-tetrahydrobenzo[4,5]thieno[2,3-d]pyrimidin-4(3H)-one (B2). Yield 80\%; m.p. ${ }^{169-171}{ }^{\circ} \mathrm{C} .{ }^{1} \mathrm{H}-\mathrm{NMR}\left(600 \mathrm{MHz}, \mathrm{CDCl}_{3}\right) \delta 9.69$ (s, $\left.1 \mathrm{H}, \mathrm{N}=\mathrm{CH}-\mathrm{Ph}\right), 8.19(\mathrm{~s}, 1 \mathrm{H}$, 2-pyrimidin-H), 8.09 (d, J = 7.8 Hz, 1H, Ph-H), $7.48(\mathrm{~m}, 1 \mathrm{H}, \mathrm{Ph}-\mathrm{H}), 7.04(\mathrm{t}, J=7.8 \mathrm{~Hz}, 1 \mathrm{H}, \mathrm{Ph}-\mathrm{H}), 6.95$ $(\mathrm{d}, J=8.4 \mathrm{~Hz}, 1 \mathrm{H}, \mathrm{Ph}-\mathrm{H}), 3.88\left(\mathrm{~s}, 3 \mathrm{H},-\mathrm{OCH}_{3}\right), 3.05(\mathrm{t}, J=6.0 \mathrm{~Hz}, 2 \mathrm{H}, 8$-Tetrahydrophenyl-H), $2.79(\mathrm{t}$, $J=6.0 \mathrm{~Hz}, 2 \mathrm{H}, 5$-Tetrahydrophenyl-H), 1.91 (m, 4H, 6,7-Tetrahydrophenyl-H); ${ }^{13} \mathrm{C}-\mathrm{NMR}(151 \mathrm{MHz}$, $\left.\mathrm{CDCl}_{3}\right) \delta 161.49,160.62,159.65,156.09,144.89,134.65,134.03,132.30,127.19,123.49,121.39,120.99$, 111.40, 55.77, 25.87, 25.46, 23.00, 22.40; ESI-MS $m / z: 340.2[\mathrm{M}+1]^{+}$, calculated for $\mathrm{C}_{18} \mathrm{H}_{17} \mathrm{~N}_{3} \mathrm{O}_{2} \mathrm{~S}: 339.4$.

(E)-3-((2,3-Dimethoxybenzylidene)amino)-5,6,7,8-tetrahydrobenzo[4,5]thieno[2,3-d]pyrimidin-4(3H)-one (B3). Yield 78\%; m.p. $226-228{ }^{\circ} \mathrm{C} .{ }^{1} \mathrm{H}-\mathrm{NMR}\left(600 \mathrm{MHz}, \mathrm{CDCl}_{3}\right) \delta 9.66(\mathrm{~s}, 1 \mathrm{H}, \mathrm{N}=\mathrm{CH}-\mathrm{Ph}), 8.19(\mathrm{~s}, 1 \mathrm{H}$, 2-pyrimidin- $\mathrm{H}), 7.68\left(\mathrm{dd}, J_{1}=7.8 \mathrm{~Hz}, J_{2}=1.2 \mathrm{~Hz}, 1 \mathrm{H}, \mathrm{Ph}-\mathrm{H}\right), 7.14(\mathrm{t}, J=7.8 \mathrm{~Hz}, 1 \mathrm{H}, \mathrm{Ph}-\mathrm{H})$, $7.07\left(\mathrm{dd}, J_{1}=8.4 \mathrm{~Hz}, J_{2}=1.2 \mathrm{~Hz}, 1 \mathrm{H}, \mathrm{Ph}-\mathrm{H}\right), 3.94\left(\mathrm{~s}, 3 \mathrm{H},-\mathrm{OCH}_{3}\right), 3.91\left(\mathrm{~s}, 3 \mathrm{H},-\mathrm{OCH}_{3}\right), 3.06(\mathrm{t}$, $J=6.0 \mathrm{~Hz}, 2 \mathrm{H}, 8$-Tetrahydrophenyl-H), $2.80(\mathrm{t}, J=6.0 \mathrm{~Hz}, 2 \mathrm{H}, 5$-Tetrahydrophenyl-H), $1.91(\mathrm{~m}, 4 \mathrm{H}$, 6,7-Tetrahydrophenyl-H); ${ }^{13} \mathrm{C}-\mathrm{NMR}\left(151 \mathrm{MHz}, \mathrm{CDCl}_{3}\right) \delta 161.31,160.60,156.09,153.04,150.47,144.98$, 134.72, 132.36, 126.85, 124.44, 123.50, 118.43, 116.12, 62.34, 56.10, 25.92, 25.48, 23.01, 22.40. ESI-MS $m / z$ : $370.2[\mathrm{M}+1]^{+}$, calculated for $\mathrm{C}_{19} \mathrm{H}_{19} \mathrm{~N}_{3} \mathrm{O}_{3} \mathrm{~S}: 369.4$.

(E)-3-((2-Hydroxy-3-methoxybenzylidene)amino)-5,6,7,8-tetrahydrobenzo[4,5]thieno[2,3-d]pyrimidin-4(3H)-one (B4). Yield 82\%; m.p. 197-199 ${ }^{\circ} \mathrm{C} .{ }^{1} \mathrm{H}-\mathrm{NMR}\left(600 \mathrm{MHz}, \mathrm{CDCl}_{3}\right) \delta 10.43$ (s, 1H, -OH), 9.42 (s, 1H, $\mathrm{N}=\mathrm{CH}-\mathrm{Ph}), 8.13$ (s, 1H, 2-Pyrimidin-H), 7.05 (m, 2H, Ph-H), 6.94 (t, J = 7.8 Hz, 1H, Ph-H), 3.94 (s, 3H, $\left.-\mathrm{OCH}_{3}\right), 3.03(\mathrm{t}, J=6.0 \mathrm{~Hz}, 2 \mathrm{H}, 8$-Tetrahydrophenyl-H), $2.80(\mathrm{t}, J=6.0 \mathrm{~Hz}, 2 \mathrm{H}, 5$-Tetrahydrophenyl-H), 1.91 (m, 4H, 6,7-Tetrahydrophenyl-H); ${ }^{13} \mathrm{C}-\mathrm{NMR}\left(151 \mathrm{MHz}, \mathrm{CDCl}_{3}\right) \delta 161.31,160.60,156.09,153.04$, $150.47,144.98,134.72,132.36,126.85,124.44,123.50,118.43,116.12,62.34,25.92,25.48,23.01,22.40$. ESI-MS $m / z: 356.2[\mathrm{M}+1]^{+}$, calculated for $\mathrm{C}_{18} \mathrm{H}_{17} \mathrm{~N}_{3} \mathrm{O}_{3} \mathrm{~S}: 355.4$.

(E)-3-((2-Nitrobenzylidene)amino)-5,6,7,8-tetrahydrobenzo[4,5]thieno[2,3-d]pyrimidin-4(3H)-one (B5). Yield 69\%; m.p. $225-227{ }^{\circ} \mathrm{C} .{ }^{1} \mathrm{H}-\mathrm{NMR}\left(600 \mathrm{MHz}, \mathrm{CDCl}_{3}\right) \delta 10.17$ (s, 1H, N=CH-Ph), 8.24 (s, 1H, 2-Pyrimidin $-\mathrm{H}), 8.15(\mathrm{~m}, 2 \mathrm{H}, \mathrm{Ph}-\mathrm{H}), 7.77(\mathrm{t}, J=7.8 \mathrm{~Hz}, 1 \mathrm{H}, \mathrm{Ph}-\mathrm{H}), 7.71(\mathrm{~m}, 1 \mathrm{H}, \mathrm{Ph}-\mathrm{H}), 3.04(\mathrm{t}, J=6.0 \mathrm{~Hz}, 2 \mathrm{H}$, 8-Tetrahydrophenyl-H), $2.81(\mathrm{t}, J=6.0 \mathrm{~Hz}, 2 \mathrm{H}, 5$-Tetrahydrophenyl-H), $1.91(\mathrm{~m}, 4 \mathrm{H}, 6,7-\mathrm{Tetrahydr}$ 
ophenyl-H); ${ }^{13} \mathrm{C}-\mathrm{NMR}\left(151 \mathrm{MHz}, \mathrm{CDCl}_{3}\right) \delta 160.49,159.73,156.43,148.86,145.36,133.95,132.55,132.51$, $132.12,129.62,128.83,125.05,123.52,25.83,25.48,22.97,22.35$. ESI-MS $m / z: 355.2[\mathrm{M}+1]^{+}$, calculated for $\mathrm{C}_{17} \mathrm{H}_{14} \mathrm{~N}_{4} \mathrm{O}_{3} \mathrm{~S}: 354.4$.

(E)-3-((2-(Trifluoromethyl)benzylidene)amino)-5,6,7,8-tetrahydrobenzo[4,5]thieno[2,3-d]pyrimidin-4(3H)-one (B6). Yield 76\%; m.p. $239-241^{\circ} \mathrm{C} .{ }^{1} \mathrm{H}-\mathrm{NMR}\left(600 \mathrm{MHz}, \mathrm{CDCl}_{3}\right) \delta 10.17$ (s, 1H, N=CH-Ph), 8.24 (s, 1H, 2-Pyrimidin-H), 8.15 (m, 2H, Ph-H), $7.77(\mathrm{t}, J=7.8 \mathrm{~Hz}, 1 \mathrm{H}, \mathrm{Ph}-\mathrm{H}), 7.71(\mathrm{~m}, 1 \mathrm{H}, \mathrm{Ph}-\mathrm{H}), 3.04(\mathrm{t}$, $J=6.0 \mathrm{~Hz}, 2 \mathrm{H}, 8$-Tetrahydrophenyl-H), $2.81(\mathrm{t}, J=6.0 \mathrm{~Hz}, 2 \mathrm{H}, 5$-Tetrahydrophenyl-H), $1.91(\mathrm{~m}, 4 \mathrm{H}$, 6,7-Tetrahydrophenyl-H); ${ }^{13} \mathrm{C}-\mathrm{NMR}\left(151 \mathrm{MHz}, \mathrm{CDCl}_{3}\right) \delta 160.36,159.26,156.51,145.56,135.08,132.56$, 132.29, 131.57, 131.48, 127.90, 126.18, 124.86, 123.51, 25.91, 25.47, 22.98, 22.34; ESI-MS $m / z: 378.1$ $[\mathrm{M}+1]^{+}, \mathrm{C}_{18} \mathrm{H}_{14} \mathrm{~F}_{3} \mathrm{~N}_{3} \mathrm{OS}: 377.4$.

(E)-3-((Naphthalen-2-ylmethylene)amino)-5,6,7,8-tetrahydrobenzo[4,5]thieno[2,3-d]pyrimidin-4(3H)-one (B7). Yield 81\%; m.p. $>250{ }^{\circ} \mathrm{C} .{ }^{1} \mathrm{H}-\mathrm{NMR}\left(600 \mathrm{MHz}, \mathrm{CDCl}_{3}\right) \delta 9.71(\mathrm{~s}, 1 \mathrm{H}, \mathrm{N}=\mathrm{CH}-\mathrm{Ph}), 8.28(\mathrm{~s}, 1 \mathrm{H}$, 2-Pyrimidin-H), 8.15 (s, $1 \mathrm{H}$, Naphthaline-H), 8.09 (dd, $J_{1}=8.4 \mathrm{~Hz}, J_{2}=1.2 \mathrm{~Hz}, 1 \mathrm{H}$, Naphthaline-H), $7.91(\mathrm{~d}, J=8.4 \mathrm{~Hz}, 2 \mathrm{H}$, Naphthaline-H), $7.88(\mathrm{~d}, J=7.8 \mathrm{~Hz}, 1 \mathrm{H}$, Naphthaline-H), 7.60-7.53 (m, $2 \mathrm{H}$, Naphthaline-H), $3.06(\mathrm{t}, J=6.0 \mathrm{~Hz}, 2 \mathrm{H}, 8$-Tetrahydrophenyl-H), $2.80(\mathrm{t}, J=6.0 \mathrm{~Hz}, 2 \mathrm{H}$, 5-Tetrahydrophenyl-H), 1.93 (m, 4H, 6,7-Tetrahydrophenyl-H); ${ }^{13} \mathrm{C}-\mathrm{NMR}\left(151 \mathrm{MHz}, \mathrm{CDCl}_{3}\right) \delta 163.85$, $160.54,156.61,145.43,135.45,134.96,133.10,132.27,130.86,129.02,128.14,126.99,123.48,122.88,25.87$, 25.47, 22.99, 22.40. ESI-MS $m / z: 360.2[\mathrm{M}+1]^{+}$, calculated for $\mathrm{C}_{21} \mathrm{H}_{17} \mathrm{~N}_{3} \mathrm{OS}: 359.4$.

(E)-3-(((1-Methyl-1H-indol-2-yl)methylene)amino)-5,6,7,8-tetrahydrobenzo[4,5]thieno[2,3-d]pyrimidin-4(3H) -one (B8). Yield 78\%; m.p. 247-249 ${ }^{\circ} \mathrm{C} ;{ }^{1} \mathrm{H}-\mathrm{NMR}\left(600 \mathrm{MHz}, \mathrm{CDCl}_{3}\right) \delta 9.25$ (s, $1 \mathrm{H}, \mathrm{N}=\mathrm{CH}-\mathrm{Ph}$ ), 8.35 (d, $J=7.8 \mathrm{~Hz}, 1 \mathrm{H}$, Benzazole-H), $8.24(\mathrm{~s}, 1 \mathrm{H}, 2-$ Pyrimidin- $\mathrm{H}), 7.48(\mathrm{~s}, 1 \mathrm{H}$, Benzazole-H), 7.36 (dd, $J_{1}=4.8 \mathrm{~Hz}, J_{2}=1.2 \mathrm{~Hz}, 2 \mathrm{H}$, Benzazole-H), $7.31\left(\mathrm{~m}, 1 \mathrm{H}\right.$, Benzazole-H), $3.82\left(\mathrm{~s}, 3 \mathrm{H}, \mathrm{N}-\mathrm{CH}_{3}\right), 3.05(\mathrm{t}$, $J=6.0 \mathrm{~Hz}, 2 \mathrm{H}, 8$-Tetrahydrophenyl-H), $2.79(\mathrm{t}, J=6.0 \mathrm{~Hz}, 2 \mathrm{H}, 5$-Tetrahydrophenyl-H), $1.87(\mathrm{~m}, 4 \mathrm{H}$, 6,7-Tetrahydrophenyl-H); ${ }^{13} \mathrm{C}-\mathrm{NMR}\left(151 \mathrm{MHz}, \mathrm{CDCl}_{3}\right) \delta 161.44,160.72,156.36,144.89,138.23,136.33$, 134.33, 132.12, 125.39, 123.84, 123.50, 123.14, 122.27, 110.58, 109.87, 33.57, 25.87, 25.46, 23.02, 22.43; ESI-MS $m / z: 363.3[\mathrm{M}+1]^{+}$, calculated for $\mathrm{C}_{20} \mathrm{H}_{18} \mathrm{~N}_{4} \mathrm{OS}: 362.4$.

(E)-3-((Furan-2-ylmethylene)amino)-5,6,7,8-tetrahydrobenzo[4,5]thieno[2,3-d]pyrimidin-4(3H)-one (B9). Yield $78 \%$; m.p. $>250{ }^{\circ} \mathrm{C} .{ }^{1} \mathrm{H}-\mathrm{NMR}\left(600 \mathrm{MHz}, \mathrm{CDCl}_{3}\right) \delta 9.52$ (s, 1H, N=CH-Ph), 8.24 (s, 1H, 2-Pyrimidin-H), $7.66\left(\mathrm{~d}, J=1.8 \mathrm{~Hz}, 1 \mathrm{H}\right.$, Furan-H), $7.05\left(\mathrm{~m}, 1 \mathrm{H}\right.$, Furan-H), 6.59 (dd, $J_{1}=3.6 \mathrm{~Hz}, J_{2}=1.8 \mathrm{~Hz}, 1 \mathrm{H}$, Furan-H), $3.03(\mathrm{t}, J=6.0 \mathrm{~Hz}, 2 \mathrm{H}, 8$-Tetrahydrophenyl-H), $2.79(\mathrm{t}, J=6.0 \mathrm{~Hz}, 2 \mathrm{H}, 5$-Tetrahydrophenyl-H), 1.95 (m, 4H, 6,7-Tetrahydrophenyl-H); ${ }^{13} \mathrm{C}-\mathrm{NMR}\left(151 \mathrm{MHz}, \mathrm{CDCl}_{3}\right) \delta 160.47,156.81,151.58,148.36,146.74$, 145.52, 135.10, 132.27, 123.38, 118.76, 112.64, 25.84, 25.47, 22.97, 22.38. ESI-MS $m / z: 300.1[\mathrm{M}+1]^{+}$, calculated for $\mathrm{C}_{15} \mathrm{H}_{13} \mathrm{~N}_{3} \mathrm{O}_{2} \mathrm{~S}: 299.4$.

3-((E)-((E)-3-(Furan-2-yl)allylidene)amino)-5,6,7,8-tetrahydrobenzo[4,5]thieno[2,3-d]pyrimidin-4(3H)-one (B10). Yield 81\%; m.p. 218-220 ${ }^{\circ} \mathrm{C} ;{ }^{1} \mathrm{H}-\mathrm{NMR}\left(600 \mathrm{MHz}, \mathrm{CDCl}_{3}\right) \delta 9.18(\mathrm{~d}, J=9.0 \mathrm{~Hz}, 1 \mathrm{H}, \mathrm{N}=\mathrm{CH}-\mathrm{Ph})$, 8.13 (s, 1H, 2-Pyrimidin-H), 7.52 (d, $J=1.8 \mathrm{~Hz}, 1 \mathrm{H}$, Furan-H), $6.94(\mathrm{~d}, J=15.6 \mathrm{~Hz}, 1 \mathrm{H}, \mathrm{CH}=\mathrm{CH}), 6.88$ $\left(\mathrm{dd}, J_{1}=15.6 \mathrm{~Hz}, J_{2}=9.0 \mathrm{~Hz}, 1 \mathrm{H}, \mathrm{CH}=\mathrm{CH}\right), 6.59\left(\mathrm{~d}, J=3.6 \mathrm{~Hz}, 1 \mathrm{H}\right.$, Furan-H), $6.49\left(\mathrm{dd}, J_{1}=3.6 \mathrm{~Hz}\right.$, $J_{2}=1.8 \mathrm{~Hz}, 1 \mathrm{H}$, Furan-H), $3.03(\mathrm{t}, J=6.0 \mathrm{~Hz}, 2 \mathrm{H}, 8$-Tetrahydrophenyl-H), $2.79(\mathrm{t}, J=6.0 \mathrm{~Hz}, 2 \mathrm{H}$, 5-Tetrahydrophenyl-H), 1.91 (m, 4H, 6,7-Tetrahydrophenyl-H); ${ }^{13} \mathrm{C}-\mathrm{NMR}\left(151 \mathrm{MHz}, \mathrm{CDCl}_{3}\right) \delta 165.51$, 160.54, 156.45, 151.73, 145.10, 144.88, 134.90, 132.27, 131.82, 123.42, 122.52, 113.95, 112.56, 25.86, 25.47, 22.99, 22.40; ESI-MS $m / z: 326.1[\mathrm{M}+1]^{+}$, calculated for $\mathrm{C}_{17} \mathrm{H}_{15} \mathrm{~N}_{3} \mathrm{O}_{2} \mathrm{~S}: 325.4$.

(E)-3-((4-(Benzyloxy)benzylidene)amino)-5,6,7,8-tetrahydrobenzo[4,5]thieno[2,3-d]pyrimidin-4(3H)-one (B11). Yield 71\%; m.p. $\quad>250{ }^{\circ} \mathrm{C}$; ${ }^{1} \mathrm{H}-\mathrm{NMR}\left(600 \mathrm{MHz}, \mathrm{CDCl}_{3}\right) \delta 9.32(\mathrm{~s}, 1 \mathrm{H}, \mathrm{N}=\mathrm{CH}-\mathrm{Ph}), 8.18(\mathrm{~s}, 1 \mathrm{H}$, 2-Pyrimidin-H), $7.79\left(\mathrm{dd}, J_{1}=19.2 \mathrm{~Hz}, J_{2}=8.4 \mathrm{~Hz}, 2 \mathrm{H}, \mathrm{Ph}-\mathrm{H}\right), 7.47(\mathrm{~m}, 5 \mathrm{H}, \mathrm{Ph}-\mathrm{H}), 7.04\left(\mathrm{dd}, J_{1}=12.6 \mathrm{~Hz}\right.$, $\left.J_{2}=9.0 \mathrm{~Hz}, 2 \mathrm{H}, \mathrm{Ph}-\mathrm{H}\right), 5.13\left(\mathrm{~d}, J=9.6 \mathrm{~Hz}, 2 \mathrm{H},-\mathrm{CH}_{2}-\right), 3.04(\mathrm{t}, J=6.0 \mathrm{~Hz}, 2 \mathrm{H}, 8$-Tetrahydrophenyl-H), 2.79 $\left(\mathrm{t}, J=6.0 \mathrm{~Hz}, 2 \mathrm{H}, 5\right.$-Tetrahydrophenyl-H), 1.95 (m, 4H, 6,7-Tetrahydrophenyl-H); ${ }^{13} \mathrm{C}-\mathrm{NMR}(151 \mathrm{MHz}$, $\left.\mathrm{CDCl}_{3}\right) \delta 164.26,162.32,156.40,146.16,145.07,136.38,134.80,130.71,130.28,128.84,128.38,127.64$, 
$125.87,123.45,115.41,115.28,70.32,25.86,25.47,22.99,22.40$. ESI-MS $m / z: 416.3[\mathrm{M}+1]^{+}$, calculated for $\mathrm{C}_{24} \mathrm{H}_{21} \mathrm{~N}_{3} \mathrm{O}_{2} \mathrm{~S}: 415.5$.

(E)-3-((4-(Dimethylamino)benzylidene)amino)-5,6,7,8-tetrahydrobenzo[4,5]thieno[2,3-d]pyrimidin-4(3H)-one (B12). Yield 83\%; m.p. 209-211 ${ }^{\circ} \mathrm{C} ;{ }^{1} \mathrm{H}-\mathrm{NMR}\left(600 \mathrm{MHz}, \mathrm{CDCl}_{3}\right) \delta 8.99(\mathrm{~s}, 1 \mathrm{H}, \mathrm{N}=\mathrm{CH}-\mathrm{Ph}), 8.16(\mathrm{~s}, 1 \mathrm{H}$, 2-Pyrimidin-H), $7.72(\mathrm{~d}, J=9.0 \mathrm{~Hz}, 2 \mathrm{H}, \mathrm{Ph}-\mathrm{H}), 6.71(\mathrm{~d}, J=9.0 \mathrm{~Hz}, 2 \mathrm{H}, \mathrm{Ph}-\mathrm{H}), 3.07\left(\mathrm{~s}, 6 \mathrm{H}, \mathrm{N}_{-} \mathrm{CH}_{3}\right)$, 3.05-3.03 (t, $J=6.0 \mathrm{~Hz}, 2 \mathrm{H}, 8$-Tetrahydrophenyl-H), $2.79(\mathrm{t}, J=6.0 \mathrm{~Hz}, 2 \mathrm{H}, 5$-Tetrahydrophenyl-H), 1.90 (m, 4H, 6,7-Tetrahydrophenyl-H); ${ }^{13} \mathrm{C}-\mathrm{NMR}\left(151 \mathrm{MHz}, \mathrm{CDCl}_{3}\right) \delta$ 166.14, 160.70, 156.27, 153.33, 146.16, $144.70,134.45,132.18,130.78,123.46,119.98,111.64,111.46,40.23,25.87,25.48,23.03,22.43$. ESI-MS $m / z$ : $353.2[\mathrm{M}+1]^{+}$, calculated for $\mathrm{C}_{19} \mathrm{H}_{20} \mathrm{~N}_{4} \mathrm{OS}: 352.4$.

(E)-3-((4-Isopropylbenzylidene)amino)-5,6,7,8-tetrahydrobenzo[4,5]thieno[2,3-d]pyrimidin-4(3H)-one (B13). Yield 79\%; m.p. 214-216 ${ }^{\circ} \mathrm{C} ;{ }^{1} \mathrm{H}-\mathrm{NMR}\left(600 \mathrm{MHz}, \mathrm{CDCl}_{3}\right) \delta 9.46(\mathrm{~s}, 1 \mathrm{H}, \mathrm{N}=\mathrm{CH}-\mathrm{Ph}), 8.21(\mathrm{~s}, 1 \mathrm{H}$, 2-Pyrimidin-H), 7.78 (d, J = 8.4 Hz, 2H, Ph-H), $7.33(\mathrm{~d}, J=8.4 \mathrm{~Hz}, 2 \mathrm{H}, \mathrm{Ph}-\mathrm{H}), 3.04(\mathrm{t}, J=6.0 \mathrm{~Hz}$, $2 \mathrm{H}, 8$-Tetrahydrophenyl-H), $2.98\left(\mathrm{td}, J_{1}=13.8 \mathrm{~Hz}, J_{2}=7.2 \mathrm{~Hz}, 1 \mathrm{H}, \mathrm{CH}\right), 2.79(\mathrm{t}, J=6.0 \mathrm{~Hz}, 2 \mathrm{H}$, 5-Tetrahydrophenyl-H), 1.93 (m, 4H, 6,7-Tetrahydrophenyl-H), $1.28\left(\mathrm{~d}, J=7.2 \mathrm{~Hz}, 6 \mathrm{H}, \mathrm{CH}_{3}\right) ;{ }^{13} \mathrm{C}-\mathrm{NMR}$ $\left(151 \mathrm{MHz}, \mathrm{CDCl}_{3}\right) \delta 164.29,160.56,156.49,153.94,145.28,134.82,132.25,130.77,128.94,127.20,123.46$, 34.44, 25.86, 25.46, 23.86, 22.98, 22.39; ESI-MS $m / z: 352.3[\mathrm{M}+1]^{+}$, calculated for $\mathrm{C}_{20} \mathrm{H}_{21} \mathrm{~N}_{3} \mathrm{OS}: 351.4$.

(E)-3-((4-(Tert-butyl)benzylidene)amino)-5,6,7,8-tetrahydrobenzo[4,5]thieno[2,3-d]pyrimidin-4(3H)-one (B14). Yield 85\%; m.p. $230-232{ }^{\circ} \mathrm{C} ;{ }^{1} \mathrm{H}-\mathrm{NMR}\left(600 \mathrm{MHz}, \mathrm{CDCl}_{3}\right) \delta 9.47(\mathrm{~s}, 1 \mathrm{H}, \mathrm{N}=\mathrm{CH}-\mathrm{Ph}), 8.21(\mathrm{~s}, 1 \mathrm{H}$, 2-Pyrimidin-H), $7.79(\mathrm{~d}, J=8.4 \mathrm{~Hz}, 2 \mathrm{H}, \mathrm{Ph}-\mathrm{H}), 7.50(\mathrm{~d}, J=8.4 \mathrm{~Hz}, 2 \mathrm{H}, \mathrm{Ph}-\mathrm{H}), 3.05(\mathrm{~m}, 2 \mathrm{H}$, 8-Tetrahydrophenyl-H), 2.80 (m, 2H, 5-Tetrahydrophenyl-H), 1.94 (m, 4H, 6,7-Tetrahydrophenyl-H), $1.36\left(\mathrm{~s}, 9 \mathrm{H}, \mathrm{CH}_{3}\right) ;{ }^{13} \mathrm{C}-\mathrm{NMR}\left(151 \mathrm{MHz}, \mathrm{CDCl}_{3}\right) \delta 164.18,160.02,156.53,156.19,145.33,134.85,132.27$, 130.41, 128.67, 126.07, 123.49, 112.29, 35.28, 31.28, 25.88, 25.48, 23.00, 22.40; ESI-MS $m / z: 366.3[\mathrm{M}+1]^{+}$, calculated for $\mathrm{C}_{21} \mathrm{H}_{23} \mathrm{~N}_{3} \mathrm{OS}$ : 365.4 .

(E)-3-((2,6-Difluorobenzylidene)amino)-5,6,7,8-tetrahydrobenzo[4,5]thieno[2,3-d]pyrimidin-4(3H)-one (B15). Yield 78\%; m.p. $218-220{ }^{\circ} \mathrm{C} ;{ }^{1} \mathrm{H}-\mathrm{NMR}\left(600 \mathrm{MHz}, \mathrm{CDCl}_{3}\right) \delta 9.96(\mathrm{~d}, J=1.8 \mathrm{~Hz}, 1 \mathrm{H}, \mathrm{N}=\mathrm{CH}-\mathrm{Ph})$, $8.23(\mathrm{~s}, 1 \mathrm{H}, 2-\mathrm{Py}$ rimidin- $\mathrm{H}), 7.78(\mathrm{~m}, 1 \mathrm{H}, \mathrm{Ph}-\mathrm{H}), 7.22(\mathrm{~m}, 1 \mathrm{H}, \mathrm{Ph}-\mathrm{H}), 7.13(\mathrm{~m}, 1 \mathrm{H}, \mathrm{Ph}-\mathrm{H}), 3.05(\mathrm{t}$, $J=6.0 \mathrm{~Hz}, 2 \mathrm{H}, 8$-Tetrahydrophenyl-H), $2.80(\mathrm{t}, J=6.0 \mathrm{~Hz}, 2 \mathrm{H}, 5$-Tetrahydrophenyl-H), $1.94(\mathrm{~m}, 4 \mathrm{H}$, 6,7-Tetrahydrophenyl-H); ${ }^{13} \mathrm{C}-\mathrm{NMR}\left(151 \mathrm{MHz}, \mathrm{CDCl}_{3}\right) \delta 160.39,156.71,155.13,145.68,135.28,132.44$, $123.45,113.01,112.85,111.48,25.87,25.48,22.97,22.36$; ESI-MS $m / z: 346.2[\mathrm{M}+1]^{+}$, calculated for $\mathrm{C}_{17} \mathrm{H}_{13} \mathrm{~F}_{2} \mathrm{~N}_{3} \mathrm{OS}$ : 345.4.

(E)-3-((2-Chloro-6-fluorobenzylidene)amino)-5,6,7,8-tetrahydrobenzo[4,5] thieno[2,3-d]pyrimidin-4(3H)-one (B16). Yield 76\%; m.p. 226-228 ${ }^{\circ} \mathrm{C} ;{ }^{1} \mathrm{H}-\mathrm{NMR}\left(600 \mathrm{MHz}, \mathrm{CDCl}_{3}\right) \delta 9.99$ (s, $\left.1 \mathrm{H}, \mathrm{N}=\mathrm{CH}-\mathrm{Ph}\right), 8.22(\mathrm{~s}, 1 \mathrm{H}$, 2-Pyrimidin-H), 7.39 (m, 1H, Ph-H), 7.30 (d, J = 8.4 Hz, 1H, Ph-H), $7.13(\mathrm{t}, J=9.0 \mathrm{~Hz}, 1 \mathrm{H}, \mathrm{Ph}-\mathrm{H}), 3.06$ $(\mathrm{t}, J=6.0 \mathrm{~Hz}, 2 \mathrm{H}, 8$-Tetrahydrophenyl-H), $2.80(\mathrm{t}, J=6.0 \mathrm{~Hz}, 2 \mathrm{H}, 5$-Tetrahydrophenyl-H), $1.92(\mathrm{~m}$, $4 \mathrm{H}, 6$,7-Tetrahydrophenyl-H); ${ }^{13} \mathrm{C}-\mathrm{NMR}\left(151 \mathrm{MHz}, \mathrm{CDCl}_{3}\right) \delta 162.25,160.51,159.29,156.66,145.81$, $135.05,32.88,132.46,129.48,125.43,123.53,116.26,116.11,25.91,25.46,22.97,22.34$; ESI-MS $m / z: 362.2$ $[\mathrm{M}+1]^{+}$, calculated for $\mathrm{C}_{17} \mathrm{H}_{13} \mathrm{ClFN}_{3} \mathrm{OS}: 361.8$.

(E)-3-((2-Bromo-6-fluorobenzylidene)amino)-5,6,7,8-tetrahydrobenzo[4,5]thieno[2,3-d]pyrimidin-4(3H)-one (B17). Yield 71\%; m.p. 207-209 ${ }^{\circ} \mathrm{C} ;{ }^{1} \mathrm{H}-\mathrm{NMR}\left(600 \mathrm{MHz}, \mathrm{CDCl}_{3}\right) \delta 9.96(\mathrm{~s}, 1 \mathrm{H}, \mathrm{N}=\mathrm{CH}-\mathrm{Ph}), 8.22(\mathrm{~s}, 1 \mathrm{H}$, 2-Pyrimidin-H), 7.49 (d, J = 8.4 Hz, 1H, Ph-H), $7.31(\mathrm{~m}, 1 \mathrm{H}, \mathrm{Ph}-\mathrm{H}), 7.17$ (t, J = 9.0 Hz, 1H, Ph-H), 3.05 (t, $J=6.0 \mathrm{~Hz}, 2 \mathrm{H}, 8$-Tetrahydrophenyl-H), $2.79(\mathrm{t}, J=6.0 \mathrm{~Hz}, 2 \mathrm{H}, 5$-Tetrahydrophenyl-H), $1.90(\mathrm{~m}, 4 \mathrm{H}$, 6,7-Tetrahydrophenyl-H); ${ }^{13} \mathrm{C}-\mathrm{NMR}\left(151 \mathrm{MHz}, \mathrm{CDCl}_{3}\right) \delta 162.25,160.51,159.29,156.66,145.81,135.05$, $32.88,132.46,129.48,125.43,123.53,116.26,116.11,25.91,25.46,22.97,22.34$; ESI-MS $m / z: 406.1,408.1$ $[\mathrm{M}+1]^{+}$, calculated for $\mathrm{C}_{17} \mathrm{H}_{13} \mathrm{BrFN}_{3} \mathrm{OS}:$ 406.2.

(E)-3-((2,5-Dibromobenzylidene)amino)-5,6,7,8-tetrahydrobenzo[4,5]thieno[2,3-d]pyrimidin-4(3H)-one (B18). Yield 75\%; m.p. 199-201 ${ }^{\circ} \mathrm{C} ;{ }^{1} \mathrm{H}-\mathrm{NMR}\left(600 \mathrm{MHz}, \mathrm{CDCl}_{3}\right) \delta 10.13$ (s, 1H, N=CH-Ph), 8.26 (d, J = 2.4 Hz, $1 \mathrm{H}, \mathrm{Ph}-\mathrm{H}), 8.25\left(\mathrm{~s}, 1 \mathrm{H}, 2\right.$-Pyrimidin-H), $7.51(\mathrm{~d}, J=8.4 \mathrm{~Hz}, 1 \mathrm{H}, \mathrm{Ph}-\mathrm{H}), 7.46\left(\mathrm{dd}, J_{1}=8.4 \mathrm{~Hz}, J_{2}=2.4 \mathrm{~Hz}\right.$, 
1H, Ph-H), $3.06(\mathrm{t}, J=6.0 \mathrm{~Hz}, 2 \mathrm{H}, 8$-Tetrahydrophenyl-H), $2.80(\mathrm{t}, J=6.0 \mathrm{~Hz}, 2 \mathrm{H}, 5$-Tetrahydrophenyl-H), $1.92\left(\mathrm{~m}, 4 \mathrm{H}, 6,7-\right.$ Tetrahydrophenyl-H); ${ }^{13} \mathrm{C}-\mathrm{NMR}\left(151 \mathrm{MHz}, \mathrm{CDCl}_{3}\right) \delta 160.34,159.81,156.80,145.83$, $135.84,135.25,134.84,134.52,132.51,130.88,124.68,123.47,122.02,25.94,25.48,22.97,22.34$; ESI-MS $m / z: 468.0[\mathrm{M}+1]^{+}$, calculated for $\mathrm{C}_{17} \mathrm{H}_{13} \mathrm{Br}_{2} \mathrm{~N}_{3} \mathrm{OS}: 467.2$.

(E)-4-(((4-Oxo-5,6,7,8-tetrahydrobenzo[4,5]thieno[2,3-d]pyrimidin-3(4H)-yl)imino)methyl)phenyl acetate (B19). Yield 76\%; m.p. $215-217^{\circ} \mathrm{C} ;{ }^{1} \mathrm{H}-\mathrm{NMR}\left(600 \mathrm{MHz}, \mathrm{CDCl}_{3}\right) \delta 9.60(\mathrm{~s}, 1 \mathrm{H}, \mathrm{N}=\mathrm{CH}-\mathrm{Ph}), 8.22(\mathrm{~s}, 1 \mathrm{H}$, 2-Pyrimidin-H), $7.88(\mathrm{~d}, J=8.4 \mathrm{~Hz}, 2 \mathrm{H}, \mathrm{Ph}-\mathrm{H}), 7.22(\mathrm{~d}, J=8.4 \mathrm{~Hz}, 2 \mathrm{H}, \mathrm{Ph}-\mathrm{H}), 3.05(\mathrm{t}, J=6.0 \mathrm{~Hz}, 2 \mathrm{H}$, 8-Tetrahydrophenyl-H), $2.80\left(\mathrm{t}, J=6.0 \mathrm{~Hz}, 2 \mathrm{H}, 5\right.$-Tetrahydrophenyl-H), $2.33\left(\mathrm{~s}, 3 \mathrm{H}, \mathrm{COCH}_{3}\right), 1.91(\mathrm{~m}$, $4 \mathrm{H}, 6$,7-Tetrahydrophenyl-H); ${ }^{13} \mathrm{C}-\mathrm{NMR}\left(151 \mathrm{MHz}, \mathrm{CDCl}_{3}\right) \delta 169.07,162.43,156.67,153.81,145.49$, 135.04, 132.30, 130.90, 130.00, 125.57,122.38, 25.88, 25.48, 22.99, 22.39, 21.32. ESI-MS $m / z: 368.2[\mathrm{M}+1]^{+}$, calculated for $\mathrm{C}_{19} \mathrm{H}_{17} \mathrm{~N}_{3} \mathrm{O}_{3} \mathrm{~S}: 367.4$.

(E)-3-((4-(Allyloxy)benzylidene)amino)-5,6,7,8-tetrahydrobenzo[4,5]thieno[2,3-d]pyrimidin-4(3H)-one (B20). Yield 74\%; m.p. $178-180{ }^{\circ} \mathrm{C} ;{ }^{1} \mathrm{H}-\mathrm{NMR}\left(600 \mathrm{MHz}, \mathrm{CDCl}_{3}\right) \delta 9.32(\mathrm{~s}, 1 \mathrm{H}, \mathrm{N}=\mathrm{CH}-\mathrm{Ph}), 8.19(\mathrm{~s}, 1 \mathrm{H}$, 2-Pyrimidin-H), $7.80(\mathrm{~d}, J=9.0 \mathrm{~Hz}, 2 \mathrm{H}, \mathrm{Ph}-\mathrm{H}), 6.99(\mathrm{~d}, J=9.0 \mathrm{~Hz}, 2 \mathrm{H}, \mathrm{Ph}-\mathrm{H}), 6.07\left(\mathrm{~m}, 1 \mathrm{H}, \mathrm{CH}_{2} \mathrm{CH}=\mathrm{CH}_{2}\right)$, $5.44\left(\mathrm{dd}, J_{1}=17.4 \mathrm{~Hz}, J_{2}=1.2 \mathrm{~Hz}, 1 \mathrm{H}, \mathrm{CH}_{2} \mathrm{CH}=\mathrm{CH}_{2}\right), 5.33\left(\mathrm{dd}, J_{1}=10.2 \mathrm{~Hz}, J_{2}=1.2 \mathrm{~Hz}, 1 \mathrm{H}\right.$, $\left.\mathrm{CH}_{2} \mathrm{CH}=\mathrm{CH}_{2}\right), 4.61\left(\mathrm{~m}, 2 \mathrm{H}, \mathrm{CH}_{2} \mathrm{CH}=\mathrm{CH}_{2}\right), 3.05(\mathrm{t}, J=6.0 \mathrm{~Hz}, 2 \mathrm{H}, 8$-Tetrahydrophenyl- $\mathrm{H}), 2.80(\mathrm{t}$, $J=6.0 \mathrm{~Hz}, 2 \mathrm{H}, 5$-Tetrahydrophenyl-H), 1.95 (m, 4H, 6,7-Tetrahydrophenyl-H); ${ }^{13} \mathrm{C}-\mathrm{NMR}(600 \mathrm{MHz}$, $\left.\mathrm{CDCl}_{3}\right) \delta 164.33,162.18160 .63,156.41,145.08,134.80,132.71,132.24,130.69,125.77,123.47,118.34$, $115.27,69.07,25.87,25.48,23.01,22.41$. ESI-MS $m / z: 365.1[\mathrm{M}+1]^{+}$, calculated for $\mathrm{C}_{20} \mathrm{H}_{19} \mathrm{~N}_{3} \mathrm{O}_{2} \mathrm{~S}: 365.4$.

\subsection{Cell Viability Assay}

RAW264.7 cells were plated at $5 \times 10^{3} /$ well and cultured in complete RPMI-1640 medium containing $5 \%$ heat inactivated serum, $100 \mathrm{U} / \mathrm{mL}$ penicillin and $100 \mathrm{mg} / \mathrm{mL}$ streptomycin, in incubator under $5 \% \mathrm{CO}_{2}$ at $37{ }^{\circ} \mathrm{C}$ for $24 \mathrm{~h}$. Compounds were dissolved in DMSO and diluted with 1640 medium to the desired concentrations. Cells and compound solutions were incubated for $72 \mathrm{~h}$ together, then $5 \mathrm{mg} / \mathrm{mL}$ fresh MTT solution was added to every hole and the cells were cultured for another $3 \mathrm{~h}$ in the $\mathrm{CO}_{2}$ incubator. One hundred milliliters of DMSO was used as blank control, and the optical density was recorded at $590 \mathrm{~nm}$. Cell viability is usually expressed as the ratio of absorbance.

\subsection{Determination of Cytokines}

ELISA was prepared by adding $100 \mu \mathrm{L} /$ well mixture, which contains $40 \mu \mathrm{L}$ capture antibodies, $9 \mathrm{~mL}$ sterile water, and $1 \mathrm{~mL}$ coating buffer, and the plate was kept at $4{ }^{\circ} \mathrm{C}$ overnight. On the next day, the plate was washed with PBST three times, sealed for $1 \mathrm{~h}$ on table concentrator, and again washed with PBST three times. A mixture of 5\% sample and 95\% AD was added and the plate was incubated on table concentrator for $2 \mathrm{~h}$. Then $40 \mu \mathrm{L}$ detection antibody was mixed with $100 \mu \mathrm{L}$ AD and was added to ELISA plate $100 \mu \mathrm{L} /$ well and the ELISA plate was incubated on table concentrator for $1 \mathrm{~h}$. The wells were washed with PBST three times and HRP was added at $100 \mu \mathrm{L} /$ well, incubated on table concentrator for another $30 \mathrm{~min}$. Finally, the wells were washed with PBST five times and TMP was added at $100 \mu \mathrm{L} /$ well, kept in dark place until color changed to blue. Then, $2 \mathrm{M} \mathrm{H}_{2} \mathrm{SO}_{4}$ was added at $50 \mu \mathrm{L} /$ well to stop the reaction and the OD value was measured at $450 \mathrm{~nm}$.

\subsection{Measurement of NO Levels}

Ten microliters of cell supernatant was added to 96-well ELISA plate; $100 \mu \mathrm{L}$ Griess reagent was added and mixed well; and the plate was stewed at room temperature and kept in dark place for $10 \mathrm{~min}$. Absorbance at $540 \mathrm{~nm}$ was measured and the content of $\mathrm{NO}$ was calculated using the following formula:

Content of $\mathrm{NO}=\frac{\text { measured } \mathrm{OD} \text { value-blank OD value }}{\text { standard } \mathrm{OD} \text { value }- \text { blank OD balue }} *$ standard substance concentration $(100 \mathrm{umol} / \mathrm{L})$ $\times$ diluted multiple of sample before manage $(\mathrm{umol} / \mathrm{L})$ 


\subsection{RNA Isolation and Real-Time Reverse Transcription-Polymerase Chain Reaction (Real-Time RT-PCR)}

Ten microliters of $2 \times$ Real time PCT Master Mix, $1 \mu \mathrm{L}$ template, $2 \mu \mathrm{L}$ primer mixer, and $7 \mu \mathrm{L}$ $0.1 \%$ DEPC water were added in $0.2 \mathrm{~mL}$ PCR tube. The conditions of the RT-PCR were as follows: pre-denaturation at $95^{\circ} \mathrm{C}$ for $5 \mathrm{~min}$, degeneration at $95^{\circ} \mathrm{C}$ for $30 \mathrm{~s}$, annealing 40 cycles at $60{ }^{\circ} \mathrm{C}$ for $20 \mathrm{~s}$ or $72{ }^{\circ} \mathrm{C}$ for $40 \mathrm{~s}$. The primer sequences were as follows:

\section{GAPDH (149 bp)}

(Sense primer) $5^{\prime}$ TATGTCGTGGAGTCTACTGGT $3^{\prime}$

(Anti-sense primer) $5^{\prime}$ GAGTTGTCATATTTCTCGTGG $3^{\prime}$

COX2 (74 bp)

(Sense primer) $5^{\prime}$ TGAGCAACTATTCCAAACCAGC $3^{\prime}$

(Anti-sense primer) $5^{\prime}$ GCACGTAGTCTTCGATCACTATC $3^{\prime}$

INOS (127 bp)

(Sense primer) 5' GTTCTCAGCCCAACAATACAAGA $3^{\prime}$

(Anti-sense primer) 5' GTGGACGGGTCGATGTCAC $3^{\prime}$

\subsection{Cellular NF- $\kappa B$ p65 Translocation Assay}

The assay was performed using a cellular NF-kB p-65 translocation kit (Beyotime Biotech, Nantong, China) following the manufacturer's instructions. The red and blue fluorescence of the P65 protein and nuclei were visualized simultaneously by fluorescence microscope (Nikon, Tokyo, Japan) at an excitation wavelength of $350 \mathrm{~nm}$ for DAPI and $540 \mathrm{~nm}$ for Cy3.

\subsection{Western Blot Analysis}

The treated cells were collected and lysed. An amount of $40 \mu \mathrm{g}$ of the whole cell lysate was separated by $10 \%$ sodium dodecyl sulfate-polyacrylamide gel electrophoresis and electro-transferred to a nitrocellulose membrane. Each membrane was pre-incubated for $1 \mathrm{~h}$ at room temperature in Tris-buffered saline, $\mathrm{pH} 7.6$, containing $0.05 \%$ Tween 20 and 5\% non-fat milk. The nitrocellulose membrane was incubated with specific antibodies against p-JNK, IKB $\alpha$ p-p38, p50, p-ERK1/2, COX-2, iNOS, or GAPDH (Santa Cruz Biotech Co. Ltd. Santa Cruz, CA, USA). Immunoreactive bands were detected by incubating with secondary antibody conjugated with horseradish peroxidase and visualized using enhanced chemiluminescence reagents (Bio-Rad, Hercules, CA, USA).

\subsection{Animal Study}

Rats, obtained from Laboratory Animal Center of Wenzhou Medical University (Wenzhou, China), were used to study the anti-inflammatory activity of compounds. All experimental procedures and protocols were reviewed and approved by the Animal Care and Use Committee of Wenzhou Medical University and were in accordance with the Guide for the Care and Use of Laboratory Animals. Forty-eight SD male rats (weighting 150 to $190 \mathrm{~g}$ ) were divided into 6 groups, with 8 male rats (weighting 150 to $190 \mathrm{~g}$ ) in each group. Compounds were dissolved in $0.5 \%$ aqueous CMC solution. Groups of rats were fed for 3 days in room temperature adaptability conditions. Intragastric administration of $1 \mathrm{~mL}$ dose of the compounds was applied at $10 \mathrm{mg} / \mathrm{kg}$ per day for three consecutive days. Edema was induced by subcutaneous injection of $1 \%$ sterilized carrageenan saline solution in a volume of $0.1 \mathrm{~mL} / \mathrm{rat}$ at the right hind paws $1 \mathrm{~h}$ after the last dose. Rat paw volume was measured after carrageenan injection at $0,0.5,1,2,3,4$, and $5 \mathrm{~h}$. Measurements were repeated three times and the average was used to assess the extent of paw swelling. The inhibition rate for rat paw swelling was calculated by the following formula:

$$
\text { Inhibition rate }(\%)=\left[\left(\mathrm{V}_{\mathrm{R}}-\mathrm{V}_{0}\right)_{\text {control }}-\left(\mathrm{V}_{\mathrm{R}}-\mathrm{V}_{0}\right)_{\text {treat }}\right] /\left(\mathrm{V}_{\mathrm{R}}-\mathrm{V}_{0}\right)_{\text {control }} \times 100 \%
$$


where $V_{R}$ represents the volume of right foot for each group at each time point, and $V_{0}$ represents the volume of the right foot at $0 \mathrm{~h}$.

\subsection{Statistical Analysis}

Data are presented as the mean \pm standard error of the mean (SEM). T-test was used to analyze the differences between groups of data. Statistical analysis was performed using GraphPad Pro (GraphPad, San Diego, CA, USA). $p$ Values less than $0.05(p<0.05)$ were considered statistically significant. $p$ values less than $0.01(p<0.01)$ were considered notable statistically significant. All experiments were repeated at least three times.

\section{Conclusions}

Twenty-six tetrahydrobenzo[4,5]thieno[2,3- $d$ ]pyrimidine derivatives were synthesized. The anti-inflammatory effects of these compounds were evaluated in a variety of in vitro and in vivo assays, including the inhibition of NO, iNOS, and COX-2 production; pro-inflammatory cytokine secretion; and mRNA expression. In an effort to elucidate the potential mechanisms of anti-inflammatory activity, we also evaluated the phosphorylation of MAPK and the activation of the NF- $\kappa B$ signaling pathway in LPS-stimulated macrophages.

The results of the present study provided evidence that treatment with A2, A6, and B7 can inhibit the production of inflammatory mediators, including NO, inflammatory cytokines, iNOS, and COX-2, in LPS-stimulated RAW264.7 cells without cytotoxicity. These effects can be attributed to the inhibition of NF- $\kappa$ B activation by the degradation of $\mathrm{I} \kappa \mathrm{B} \alpha$ and $\mathrm{p} 50$ and the blockade of MAPK phosphorylation. Animal experimental findings suggest that the inhibition of carrageenan-induced rat paw edema by A6 is similar to indomethacin and celecoxib. Taken together, A6 is selected as a lead compound for further optimization and mechanistic studies.

Acknowledgments: This work was supported by a fund of the National Natural Science Foundation of China (81373262), Public Technology Applied Research Projects of Science and Technology Development of Zhejiang Province (2016C37010), Natural Science Foundation of Zhejiang Province (LY16B020010), Xinmiao Talent Project of Zhejiang Province (2016R413079), and The Opening Project of Zhejiang Provincial Top Key Discipline of Pharmaceutical Sciences $(201710,201715)$.

Author Contributions: Faqing Ye, Yuan Zhang and Lu Luo conceived and designed the experiments; Yuan Zhang, Lu Luo, Chao Han, Handeng Lv, Kaiqi Wu, Suwei Pan, Di Chen and Guoliang Shen performed the experiments; Faqing Ye, Yuan Zhang, Lu Luo, Chao Han, Handeng Lv, Kaiqi Wu, Suwei Pan, Di Chen and Guoliang Shen analyzed the data; Faqing Ye, Yuan Zhang contributed reagents/materials/analysis tools; Faqing Ye, Yuan Zhang, Lu Luo, Chao Han and Handeng Lv discussed the data and wrote the paper.

Conflicts of Interest: The authors confirm that this article content has no conflict of interests.

\section{References}

1. Hua, L.L.; Zhao, M.L.; Cosenza, M.; Kim, M.O.; Huang, H.; Tanowitz, H.B.; Brosnan, C.F.; Lee, S.C. Role of mitogen-activated protein kinases in inducible nitric oxide synthase and TNFalpha expression in human fetal astrocytes. J. Neuroimmunol. 2002, 126, 180-189. [CrossRef]

2. Pawate, S.; Shen, Q.; Fan, F.; Bhat, N.R. Redox regulation of glial inflammatory response to lipopolysaccharide and interferongamma. J. Neurosci. Res. 2004, 77, 540-551. [CrossRef] [PubMed]

3. Zhang, X.; Li, H.; Feng, H.; Xiong, H.; Zhang, L.; Song, Y.; Yu, L.; Deng, X. Valnemulin downregulates nitric oxide, prostaglandin E2, and cytokine production via inhibition of NF-kappaB and MAPK activity. Int. Immunopharmacol. 2009, 9, 810-816. [CrossRef] [PubMed]

4. Yun, K.J.; Kim, J.Y.; Kim, J.B.; Lee, K.W.; Jeong, S.Y.; Park, H.J.; Jung, H.J.; Cho, Y.W.; Yun, K.; Lee, K.T. Inhibition of LPS-induced NO and PGE2 production by asiatic acid via NF-kappa B inactivation in RAW264.7 macrophages: Possible involvement of the IKK and MAPK pathways. Int. Immunopharmacol. 2008, 8, 431-441. [CrossRef] [PubMed] 
5. Bak, M.J.; Hong, S.G.; Lee, J.W.; Jeong, W.S. Red ginseng marc oil inhibits iNOS and COX-2 via NF-kappaB and p38 pathways in LPS-stimulated RAW264.7 macrophages. Molecules 2012, 17, 13769-13786. [CrossRef] [PubMed]

6. Li, Y.; Xu, B.; Xu, M.; Chen, D.; Xiong, Y.; Lian, M.; Sun, Y.; Tang, Z.; Wang, L.; Jiang, C.; et al. 6-Gingerol protects intestinal barrier from ischemia/reperfusion-induced damage via inhibition of p38 MAPK to NF-kappaB signalling. Pharmacol. Res. 2017, 119, 137-148. [CrossRef] [PubMed]

7. Sun, P.; Zhou, K.; Wang, S.; Li, P.; Chen, S.; Lin, G.; Zhao, Y.; Wang, T. Involvement of MAPK/NF-kappaB signaling in the activation of the cholinergic anti-inflammatory pathway in experimental colitis by chronic vagus nerve stimulation. PLOS ONE 2013, 8, e69424.

8. Shi, Q.; Cao, J.; Fang, L.; Zhao, H.; Liu, Z.; Ran, J.; Zheng, X.; Li, X.; Zhou, Y.; Ge, D.; et al. Geniposide suppresses LPS-induced nitric oxide, PGE2 and inflammatory cytokine by downregulating NF-kappaB, MAPK and AP-1 signaling pathways in macrophages. Int. Immunopharmacol. 2014, 20, 298-306. [CrossRef] [PubMed]

9. Xue, J.; Chen, F.; Wang, J.; Wu, S.; Zheng, M.; Zhu, H.; Liu, Y.; He, J.; Chen, Z. Emodin protects against concanavalin A-induced hepatitis in mice through inhibiting activation of the p38 MAPK-NF-kappaB signaling pathway. Cell. Physiol. Biochem. 2015, 35, 1557-1570. [CrossRef] [PubMed]

10. Hung, Y.C.; Hsu, C.C.; Chung, C.H.; Huang, T.F. The disintegrin, trimucrin, suppresses LPS-induced activation of phagocytes primarily through blockade of NF-kappaB and MAPK activation. Naunyn-Schmiedebergs Arch. 2016, 389, 723-737. [CrossRef] [PubMed]

11. Jimenez-Jimenez, F.J.; Alonso-Navarro, H.; Herrero, M.T.; Garcia-Martin, E.; Agundez, J.A. An Update on the Role of Nitric Oxide in the Neurodegenerative Processes of Parkinson's Disease. Curr. Med. Chem. 2016, 23, 2666-2679. [CrossRef] [PubMed]

12. Bogdan, C. Nitric oxide and the immune response. Nat. Immunol. 2001, 2, 907-916. [CrossRef] [PubMed]

13. Pacher, P.; Beckman, J.S.; Liaudet, L. Nitric oxide and peroxynitrite in health and disease. Physiol. Rev. 2007, 87, 315-424. [CrossRef] [PubMed]

14. Li, L.; Hsu, A.; Moore, P.K. Actions and interactions of nitric oxide, carbon monoxide and hydrogen sulphide in the cardiovascular system and in inflammation-A tale of three gases! Pharmacol. Ther. 2009, 123, 386-400. [CrossRef] [PubMed]

15. Sorokin, A. Nitric Oxide Synthase and Cyclooxygenase Pathways: A Complex Interplay in Cellular Signaling. Curr. Med. Chem. 2016, 23, 2559-2578. [CrossRef] [PubMed]

16. Simmons, D.L.; Botting, R.M.; Hla, T. Cyclooxygenase isozymes: The biology of prostaglandin synthesis and inhibition. Pharmacol. Rev. 2004, 56, 387-437. [CrossRef] [PubMed]

17. Ricciotti, E.; FitzGerald, G.A. Prostaglandins and inflammation. Arterioscler thrombosis. Vasc. Boil. 2011, 31, 986-1000. [CrossRef] [PubMed]

18. Patrono, C.; Baigent, C. Low-dose aspirin, coxibs, and other NSAIDS: A clinical mosaic emerges. Mol. Interv. 2009, 9, 31-39. [CrossRef] [PubMed]

19. Skoutakis, V.A.; Carter, C.A.; Mickle, T.R.; Smith, V.H.; Arkin, C.R.; Alissandratos, J.; Petty, D.E. Review of diclofenac and evaluation of its place in therapy as a nonsteroidal antiinflammatory agent. Drug Intell. Clin. Pharm. 1988, 22, 850-859. [CrossRef]

20. Yamamoto, Y.; Hisa, T.; Arai, J.; Saito, Y.; Yamamoto, F.; Mukai, T.; Ohshima, T.; Maeda, M.; Ohkubo, Y. Isomeric methoxy analogs of nimesulide for development of brain cyclooxygenase-2 (COX-2)-targeted imaging agents: Synthesis, in vitro COX-2-inhibitory potency, and cellular transport properties. Bioorg. Med. Chem. 2015, 23, 6807-6814. [CrossRef] [PubMed]

21. Consalvi, S.; Biava, M.; Poce, G. COX inhibitors: A patent review (2011-2014). Expert Opin. Ther. Pat. 2015, 25, 1357-1371. [CrossRef] [PubMed]

22. Gouda, A.M.; Ali, H.I.; Almalki, W.H.; Azim, M.A.; Abourehab, M.A.; Abdelazeem, A.H. Design, Synthesis, and Biological Evaluation of Some Novel Pyrrolizine Derivatives as COX Inhibitors with Anti-Inflammatory/Analgesic Activities and Low Ulcerogenic Liability. Molecules 2016, 21, 201. [CrossRef] [PubMed]

23. Dogne, J.M.; Supuran, C.T.; Pratico, D. Adverse cardiovascular effects of the coxibs. J. Med. Chem. 2005, 48, 2251-2257. [CrossRef] [PubMed] 
24. White, W.B.; West, C.R.; Borer, J.S.; Gorelick, P.B.; Lavange, L.; Pan, S.X.; Weiner, E.; Verburg, K.M. Risk of cardiovascular events in patients receiving celecoxib: A meta-analysis of randomized clinical trials. Am. J. Cardiol. 2007, 99, 91-98. [CrossRef] [PubMed]

25. Brueggemann, L.I.; Mackie, A.R.; Mani, B.K.; Cribbs, L.L.; Byron, K.L. Differential Effects of Selective Cyclooxygenase-2 Inhibitors on Vascular Smooth Muscle Ion Channels May Account for Differences in Cardiovascular Risk Profiles. Mol. Pharm. 2009, 76, 1053-1061. [CrossRef] [PubMed]

26. Fitzgerald, G.A. Cardiovascular pharmacology of nonselective nonsteroidal anti-inflammatory drugs and coxibs: Clinical considerations. Am J. Cardiol. 2002, 89, 26d-32d. [CrossRef]

27. Solomon, S.D.; Wittes, J.; McMurray, J.; Co, A.S.C.S. Cardiovascular risk associated with celecoxib. New Engl. J. Med. 2005, 352, 2649. [CrossRef] [PubMed]

28. Cairns, J.A. The coxibs and traditional nonsteroidal anti-inflammatory drugs: A current perspective on cardiovascular risks. Can. J. Cardiol. 2007, 23, 125-131. [CrossRef]

29. Wang, X.; Chen, D.; Yu, S.; Zhang, Z.; Wang, Y.; Qi, X.; Fu, W.; Xie, Z.; Ye, F. Synthesis and Evaluation of Biological and Antitumor Activities of Tetrahydrobenzothieno[2,3- $d$ ]Pyrimidine Derivatives as Novel Inhibitors of FGFR1. Chem. Biol. Drug Des. 2016, 87, 499-507. [CrossRef] [PubMed]

30. Alagarsamy, V.; Meena, S.; Ramseshu, K.V.; Solomon, V.R.; Thirumurugan, K.; Dhanabal, K.; Murugan, M. Synthesis, analgesic, anti-inflammatory, ulcerogenic index and antibacterial activities of novel 2-methylthio-3-substituted-5,6,7,8-tetrahydrobenzo (b) thieno[2,3-d]pyrimidin-4(3H)-ones. Eur. J. Med. Chem. 2006, 41, 1293-1300. [CrossRef] [PubMed]

31. Hafez, H.N.; El-Gazzar, A.R.; Nawwar, G.A. Synthesis, biological and medicinal significance of S-glycosido-thieno[2,3-d]-pyrimidines as new anti-inflammatory and analgesic agents. Eur. J. Med. Chem. 2010, 45, 1485-1493. [CrossRef] [PubMed]

32. Ji, X.; Peng, T.; Zhang, X.; Li, J.; Yang, W.; Tong, L.; Qu, R.; Jiang, H.; Ding, J.; Xie, H.; Liu, H. Design, synthesis and biological evaluation of novel 6-alkenylamides substituted of 4-anilinothieno[2,3-d]pyrimidines as irreversible epidermal growth factor receptor inhibitors. Bioorg. Med. Chem. 2014, 22, 2366-2378. [CrossRef] [PubMed]

33. Abbas, S.E.; Abdel Gawad, N.M.; George, R.F.; Akar, Y.A. Synthesis, antitumor and antibacterial activities of some novel tetrahydrobenzo[4,5]thieno[2,3-d]pyrimidine derivatives. Eur. J. Med. Chem. 2013, 65, 195-204. [CrossRef] [PubMed]

34. Bozorov, K.; Zhao, J.Y.; Elmuradov, B.; Pataer, A.; Aisa, H.A. Recent developments regarding the use of thieno[2,3-d]pyrimidin-4-one derivatives in medicinal chemistry, with a focus on their synthesis and anticancer properties. Eur. J. Med. Chem. 2015, 102, 552-573. [CrossRef] [PubMed]

35. Kandeel, M.M.; Refaat, H.M.; Kassab, A.E.; Shahin, I.G.; Abdelghany, T.M. Synthesis, anticancer activity and effects on cell cycle profile and apoptosis of novel thieno[2,3-d]pyrimidine and thieno[3,2-e]triazolo[4,3-c]pyrimidine derivatives. Eur. J. Med. Chem. 2015, 90, 620-632. [CrossRef] [PubMed]

36. Mavrova, A.; Wesselinova, D.; Tsenov, J.A.; Lubenov, L.A. Synthesis and antiproliferative activity of some new thieno[2,3-d]pyrimidin-4(3H)-ones containing 1,2,4-triazole and 1,3,4-thiadiazole moiety. Eur. J. Med. Chem. 2014, 86, 676-683. [CrossRef] [PubMed]

37. Gangjee, A.; Li, W.; Kisliuk, R.L.; Cody, V.; Pace, J.; Piraino, J.; Makin, J. Design, synthesis, and X-ray crystal structure of classical and nonclassical 2-amino-4-oxo-5-substituted-6-ethylthieno[2,3-d]pyrimidines as dual thymidylate synthase and dihydrofolate reductase inhibitors and as potential antitumor agents. J. Med. Chem. 2009, 52, 4892-4902. [CrossRef] [PubMed]

38. Wu, C.H.; Coumar, M.S.; Chu, C.Y.; Lin, W.H.; Chen, Y.R.; Chen, C.T.; Shiao, H.Y.; Rafi, S.; Wang, S.Y.; Hsu, H.; et al. Design and synthesis of tetrahydropyridothieno[2,3- $d$ ]pyrimidine scaffold based epidermal growth factor receptor (EGFR) kinase inhibitors: The role of side chain chirality and Michael acceptor group for maximal potency. J. Med. Chem. 2010, 53, 7316-7326. [CrossRef] [PubMed]

39. Dewal, M.B.; Wani, A.S.; Vidaillac, C.; Oupicky, D.; Rybak, M.J.; Firestine, S.M. Thieno[2,3-d]pyrimidinedione derivatives as antibacterial agents. Eur. J. Med. Chem. 2012, 51, 145-153. [CrossRef] [PubMed]

40. Masaoka, T.; Chung, S.; Caboni, P.; Rausch, J.W.; Wilson, J.A.; Taskent-Sezgin, H.; Beutler, J.A.; Tocco, G.; Le Grice, S.F. Exploiting drug-resistant enzymes as tools to identify thienopyrimidinone inhibitors of human immunodeficiency virus reverse transcriptase-associated ribonuclease H. J. Med. Chem. 2013, 56, 5436-5445. [CrossRef] [PubMed] 
41. Hafez, H.N.; Hussein, H.A.; El-Gazzar, A.R. Synthesis of substituted thieno[2,3-d]pyrimidine-2,4-dithiones and their S-glycoside analogues as potential antiviral and antibacterial agents. Eur. J. Med. Chem. 2010, 45, 4026-4034. [CrossRef] [PubMed]

42. Rashad, A.E.; Ali, M.A. Synthesis and antiviral screening of some thieno[2,3- $d$ ]pyrimidine nucleosides. Nucleosides Nucleotides Nucleic Acids 2006, 25, 17-28. [CrossRef] [PubMed]

43. Deng, J.F.; Peng, L.; Zhang, G.C.; Lan, X.B.; Li, C.F.; Chen, F.X.; Zhou, Y.Y.; Lin, Z.X.; Chen, L.; Dai, R.K.; et al. The highly potent and selective dipeptidyl peptidase IV inhibitors bearing a thienopyrimidine scaffold effectively treat type 2 diabetes. Eur. J. Med. Chem. 2011, 46, 71-76. [CrossRef] [PubMed]

44. Wu, Y.L.; Yoshida, M.; Emoto, H.; Ishii, H.; Koga, K.; Tanaka, M. Effects of acute and chronic administration of MCI-225, a new selective noradrenaline reuptake inhibitor with 5-HT3 receptor blocking action, on extracellular noradrenaline levels in the hypothalamus of stressed rats. Jpn. J. Pharm. 2000, 83, 31-38. [CrossRef]

45. Kotaiah, Y.; Harikrishna, N.; Nagaraju, K.; Venkata Rao, C. Synthesis and antioxidant activity of 1,3,4-oxadiazole tagged thieno[2,3-d]pyrimidine derivatives. Eur. J. Med. Chem. 2012, 58, 340-345. [CrossRef] [PubMed]

46. Hommes, D.W.; Peppelenbosch, M.P.; van Deventer, S.J.H. Mitogen activated protein (MAP) kinase signal transduction pathways and novel anti-inflammatory targets. Gut 2003, 52, 144-151. [CrossRef] [PubMed]

Sample Availability: Samples of the compounds are not available from the authors. 